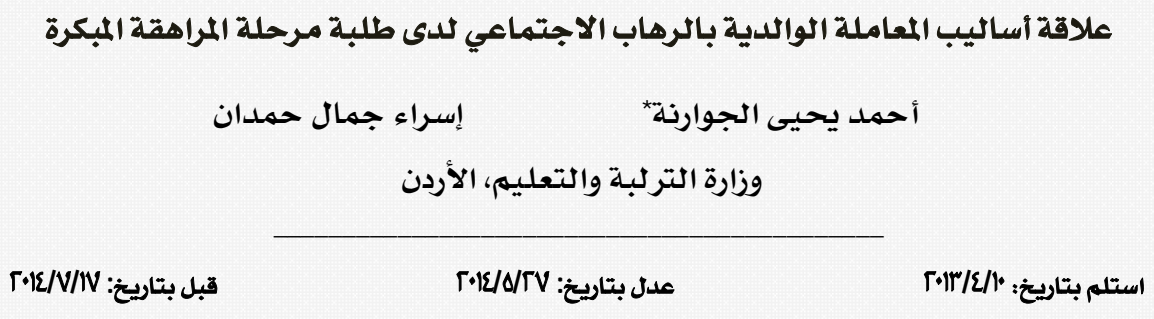

هدفت الدراسة الحالية إلى الكشف عن علاقة أساليب المعاملة الوالدية بالرهاب الاجتماعي لدى عينة من طلبة مرحلة المراهقة المبكرة. وقد

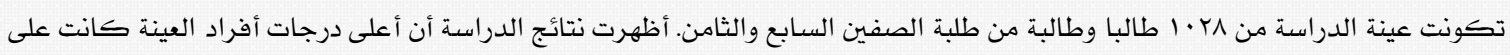

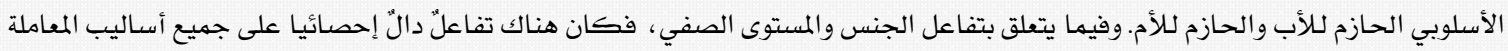
الوالدية.وأظهرت النتائج فروقا دالة إحصائيا على مقياس الرهاب الاجتماعي تعزى إلى الجنس، والمستوى الصفي، والتفاعل والتهل بينهما، بالنسبة

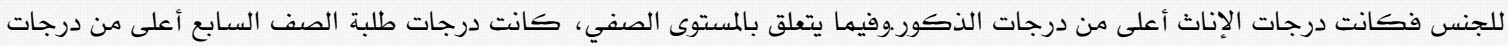

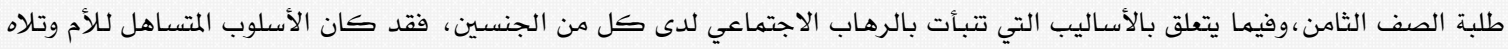

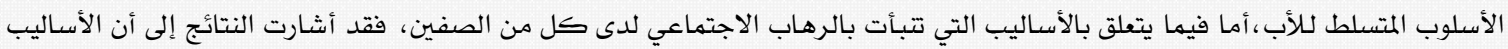

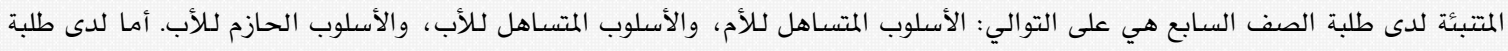

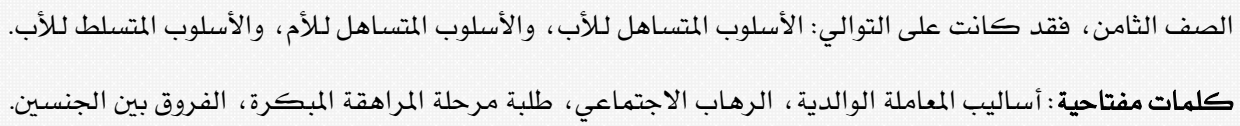

\title{
The Relationship of Parenting Styles to Social Phobia among Early Adolescent Students
}

\author{
Ahmad Y. Al-Jawarneh Esraa J. Hamdan \\ Ministry of Education, Jordan
}

This study aimed at investigating the relationship of parenting styles with social phobia among a sample of 1028 early adol escent students. To achieve the objective of the study, short forms of the parenting styles scale and a social phobia scale were used.Results showed that the participants' highest scores were on the father's authoritative and mother's authoritative parenting styles. In addition, there were significant interactions between gender and grade level on all parenting styles. The results also showed statistically significant differences in social phobia due to gender, grade level and the interaction between them, for gender was females scored higher than males. With regard to grade level seventh graders scored higher than eighth graders.The results indicated that there were significant relationships between parenting styles and social phobia, with the exception of the relationship between mother's authoritative parenting style and social phobia. Regarding the parenting styles predicting social phobia by gender, it was found that for males and females, the predictive parenting styles were: Mother's permissive parenting style and father's authoritarian parenting style. Regarding the parenting styles predicting social phobia by grade level, it was found that for seventh grade, the predictive styles were: Mother's permissive parenting style, father's permissive parenting style and father's authoritative parenting style, respectively. For eighth grade, the predictive styles were: Father's permissive parenting style, mother's permissive parenting style and father's authoritarian parenting style.

Keyw ords: Parenting styles, social phobia, early adolescents, and gender differences.

*ajawarneh24@yahoo.com 
ومن الناحية الاجتماعية، يلاحظ وجود تضارب لدى الذكر في

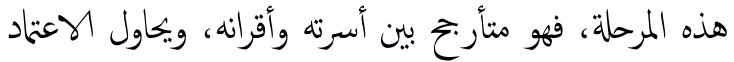

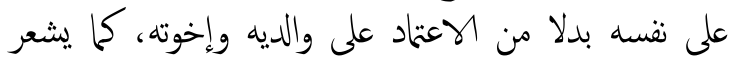

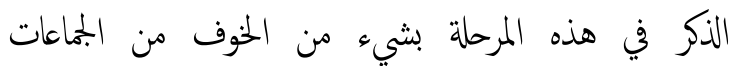

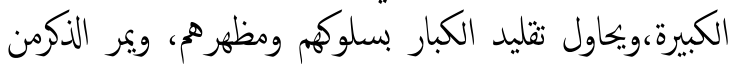

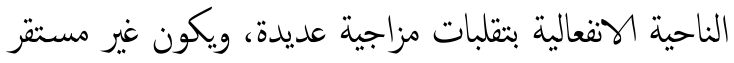

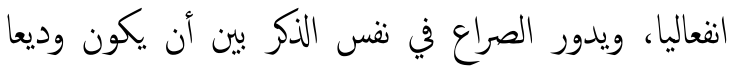

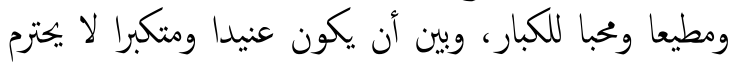

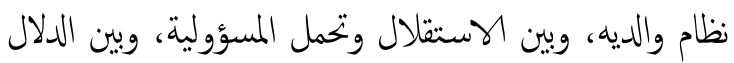

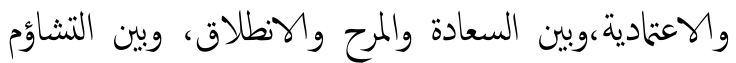

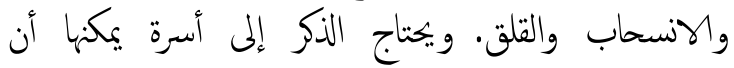

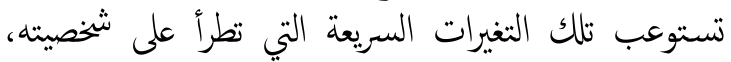

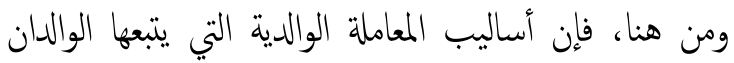

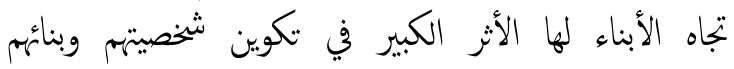

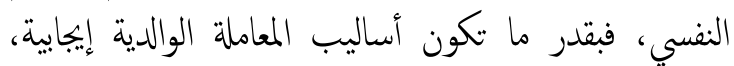

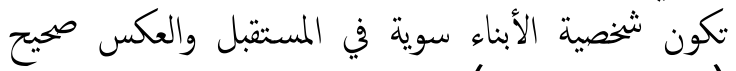

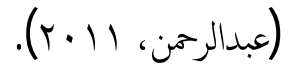

وتترك أساليب المعاملة الوالدية أثرا بالغا في تكوين شخصية الإنا الأبناء، ولا شكك أن المعاملة التي يتلقاها المراهق من والدية المايه

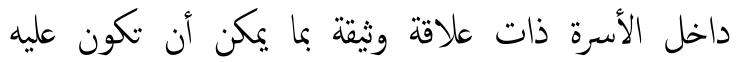

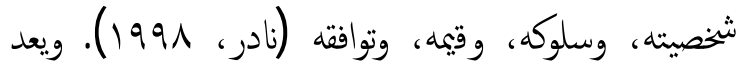

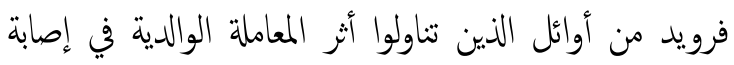

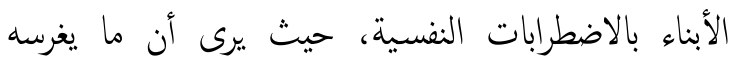

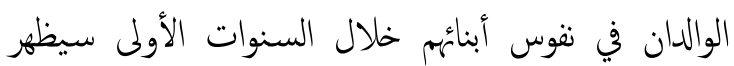

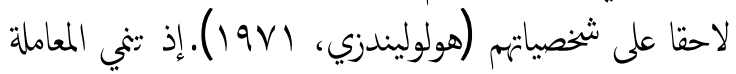

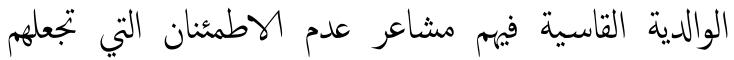

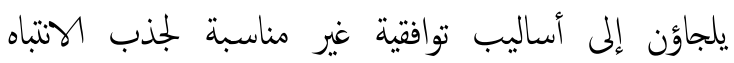

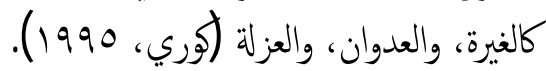

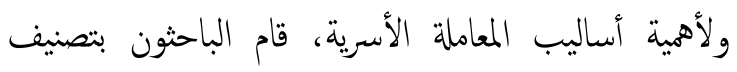

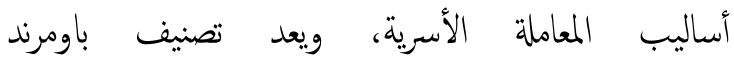
أكثرها شيوعا؛ إذ ميزت فيها أساليب (Baumrind, 1991)

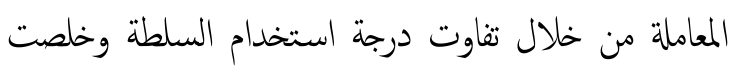

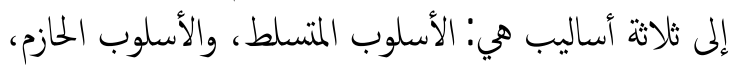

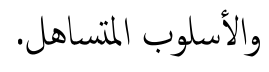

تعد المراهقة من أخطر المراحل التي يمر بها الإنسان ضمن

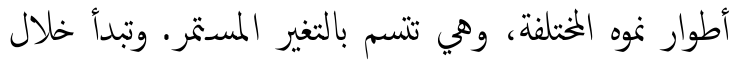

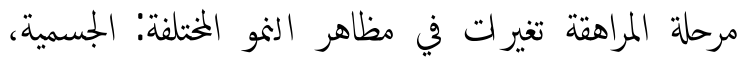

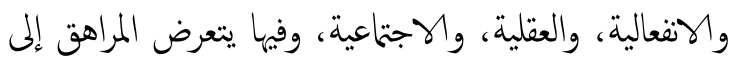

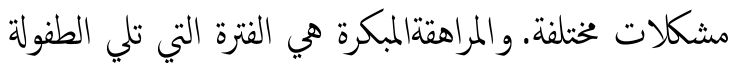

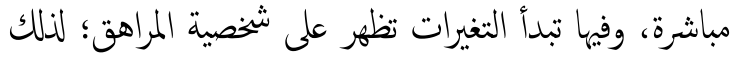

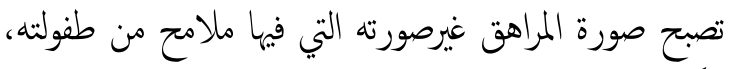

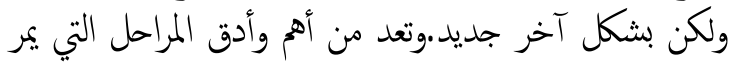

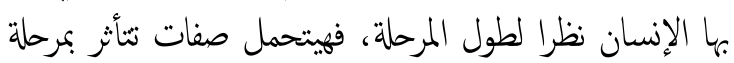
الطفولة؛ وتؤثر ثأثيرا كيرا في مراحل حياةالإنسان التالية. وكثيرا ما ينظر إلى المراهقة على أنها مشكلة وليست مرحلة

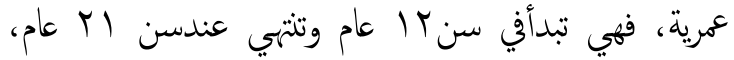
وهناك اختلاف بسيط بين الجنسين في بداية المرحلة'، فالإناث

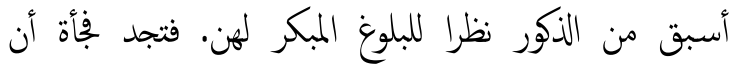

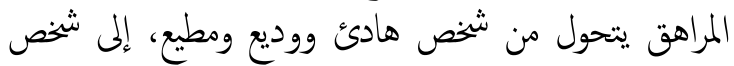

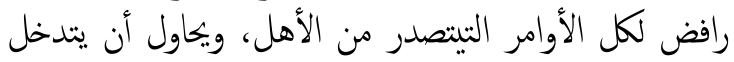

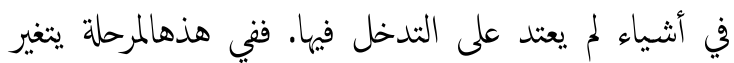

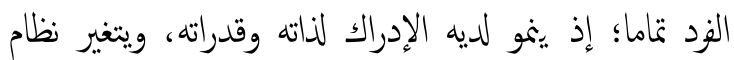

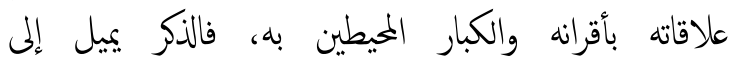

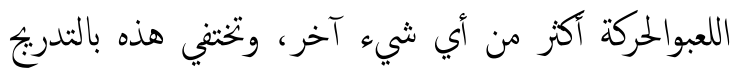

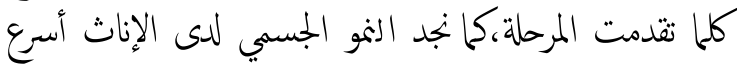

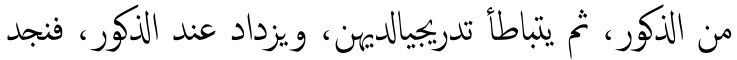

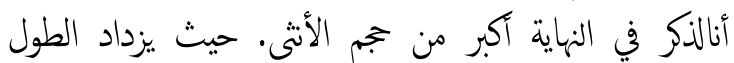
ويتسع الكتفان، ويتغير محيط الصدر وطول الساقين، و تنمو النيا

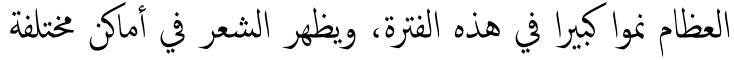

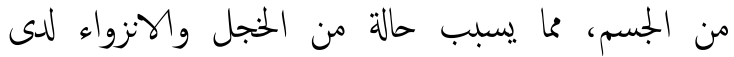

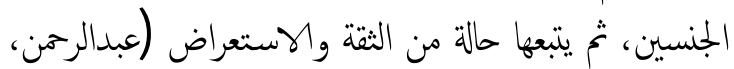
.$(r \cdot 1)$ أما بالنسبة للنمو العقلي'فتتميز هذه المرحلة بالنمو العقلي الكمي

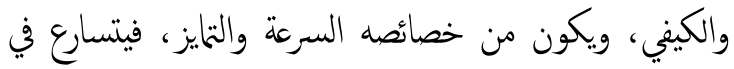
هذه المرحلة الذكاء العام وتظهر لدى الجنسين القدرة على تعلم

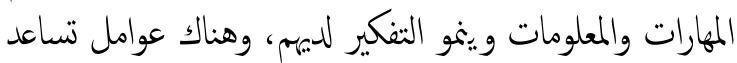

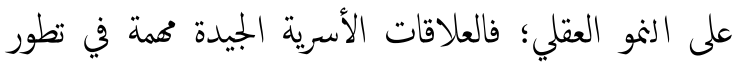

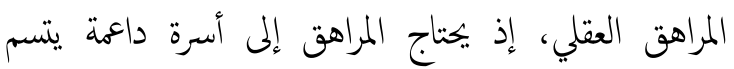
أفرادها بعقل متفتح، ومستوى تعليمي جيد. 
المتأخرة وما بعدها، وينعكس ذلك على النمو النفسي للأبناء

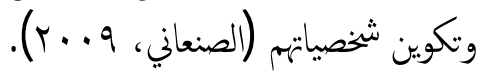

ويعد الاهتمام بأساليب المعاملة الوالدية وتنمية الأساليب

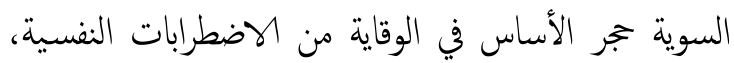

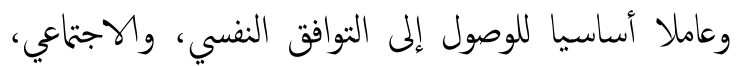

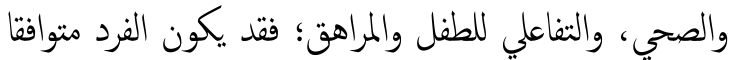

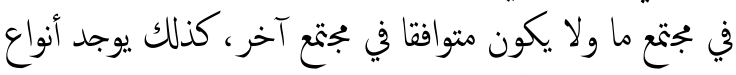

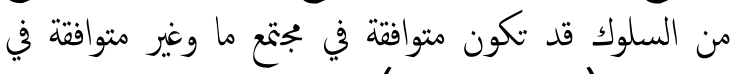

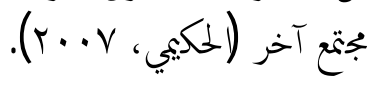

الرهاب الاجتماعي

إن الذي يعاني من الرهاب الاجتماعي يخاف من أن يظهر بشكل غريب وهو يراقب باستمرار ردود فعل الآخرين تجاهه،

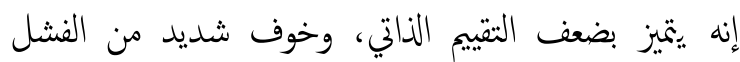
(First, Frances \& Princus, 1999) الاجتاعي استجابة انفعالية، ومعرفية لموقف أهم ما بميزه

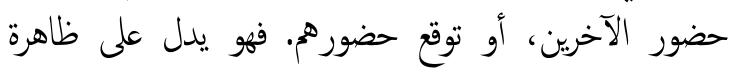

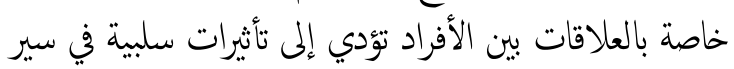

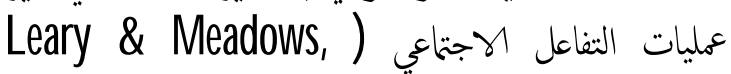

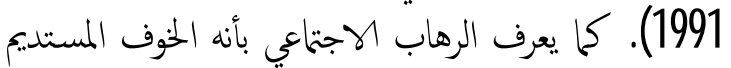
من مواقف اجتاعية، أو مواقف الأداء التي قد يتعرض فيها لأهابه الفرد لتفحص من الآخرين ويجعله يتصرف بطريقة تسبب له له اله

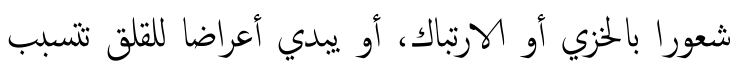

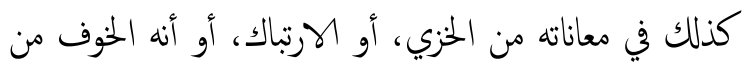

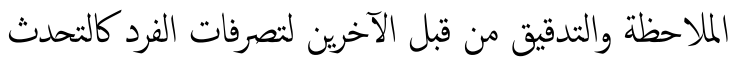

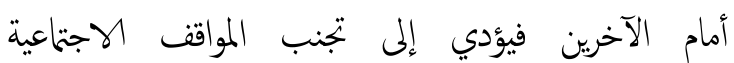

(Rachman, 1998)

ويرتبط الرهاب الاجتماعي بالسياق الثقافي للمجتمعات، ففي

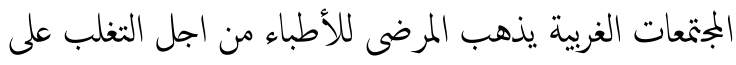

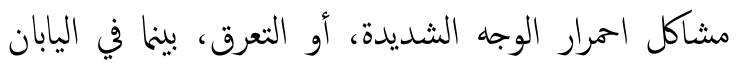

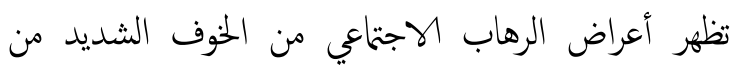

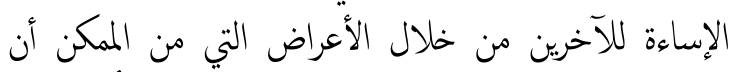

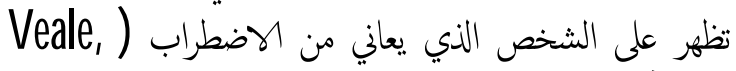

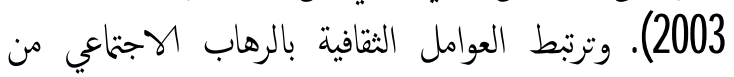

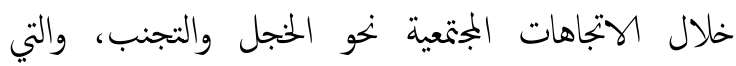

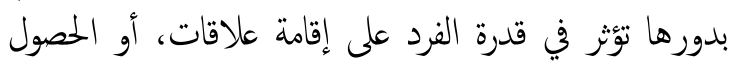

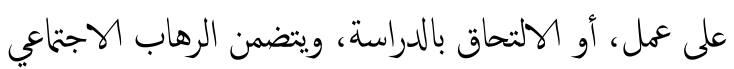

ولكل أسلوب من هذه الأساليب صفات تميزه؛ فالأسلوب

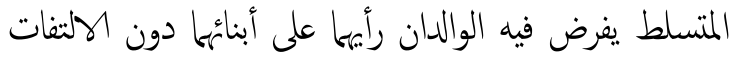

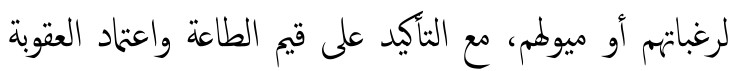

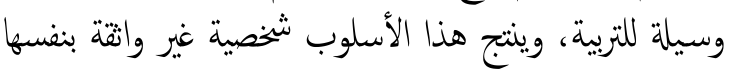

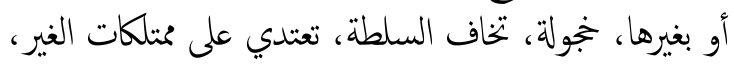

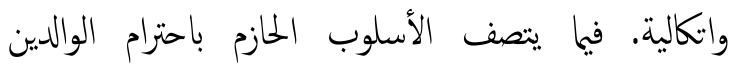

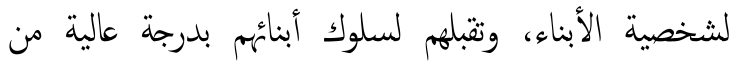

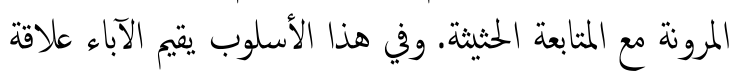

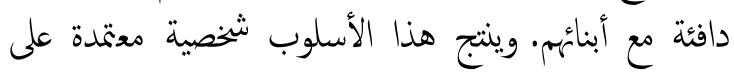

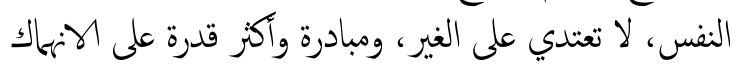

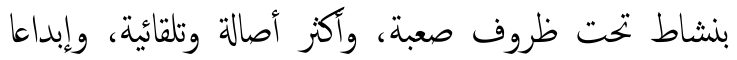

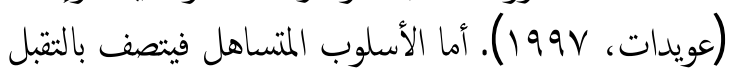
والدفء المرتفع، ويتقبل سلوك أبنائه، ونادرا ما يعاقب أو يمنع

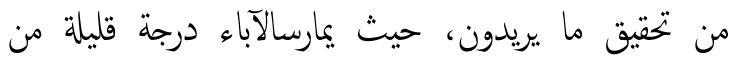
الضبط. كما أن الوالدان يطلبان من أبنائها مطالب قلب قليلة

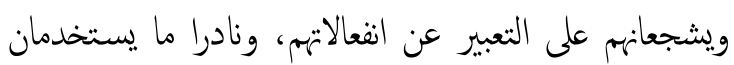

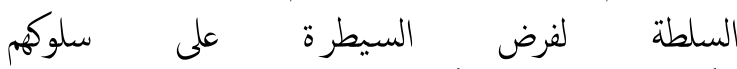

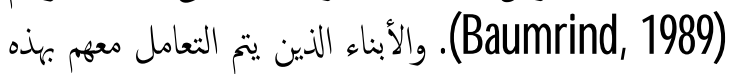

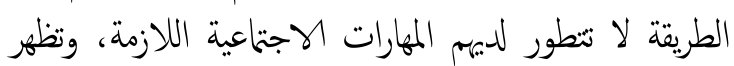
للديه اضطرابات انقعالية، بسبب غياب التوجيه والمتنابعة. وعليه فقد ربط بعض الباحثين العرب أمثال دويري

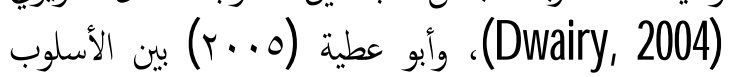

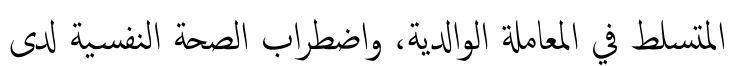

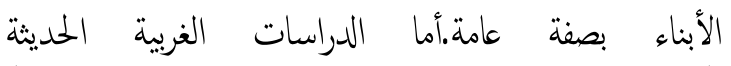
(Wenar, 1994; Bigner, 1994; Baumrind, 1991) فتربط الأسلوب التسلطي في معاملة الأبناء باضطرابات

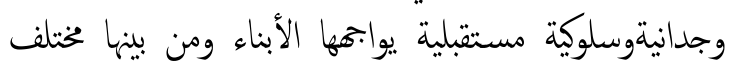

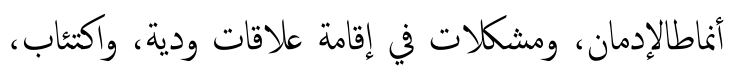

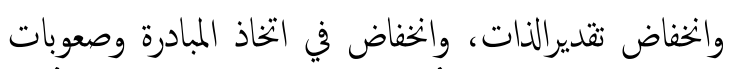

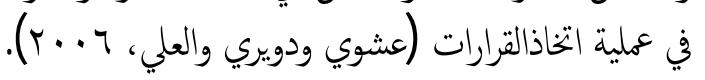

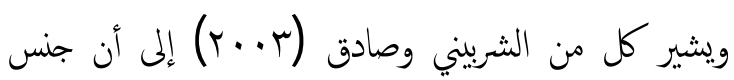

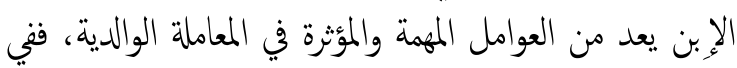

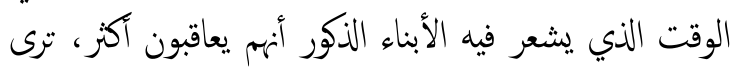

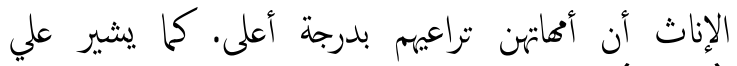
(r.V.V)

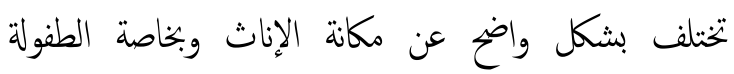




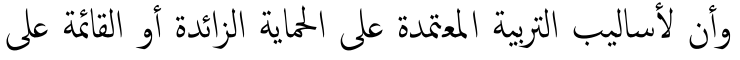

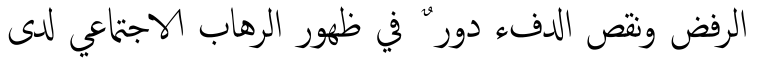

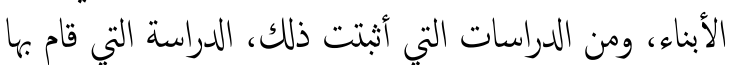

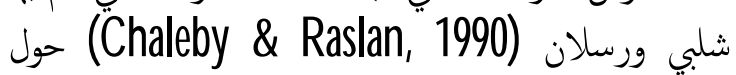

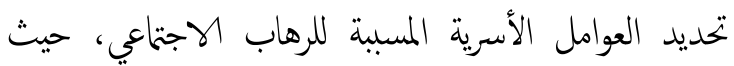

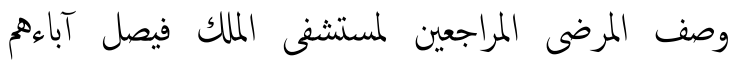

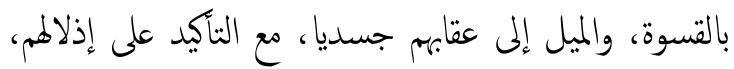

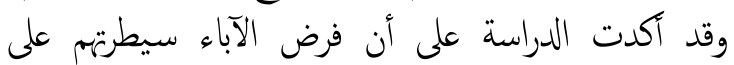

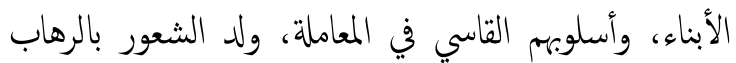

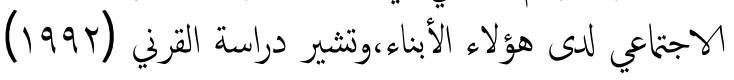

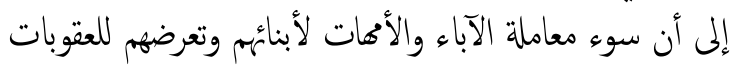

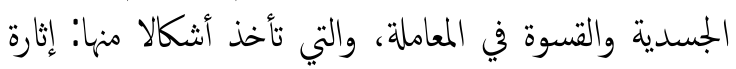

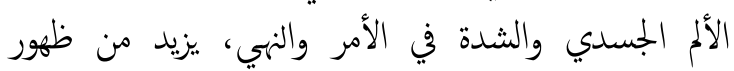

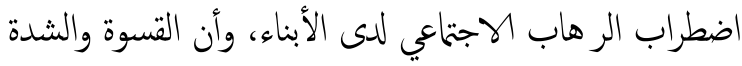

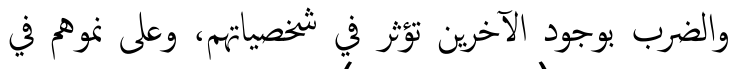

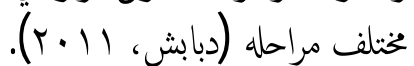

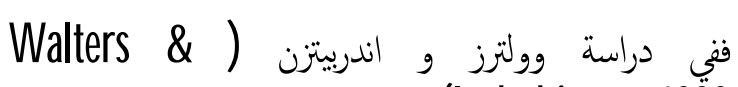
Inderbitzen, 1998

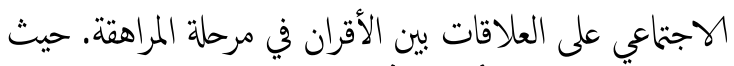

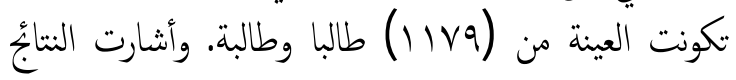
إلى أن الطالبات حصلن على درجات أعلى على مقياس الرهاب الاجتماعي، مقارنة بالطلاب.

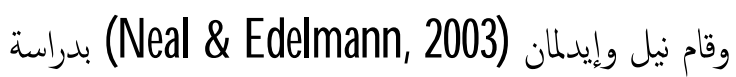
هدفت إلى الكشف عن وإن مسببات الرهاب الاجتماعي،

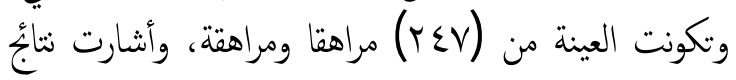

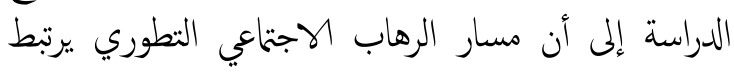

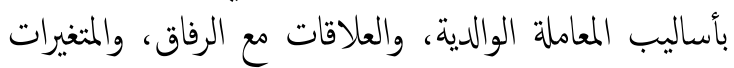

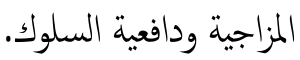

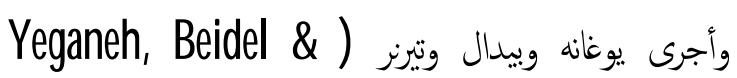
(Turner, 2006

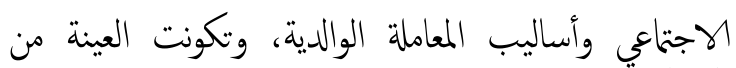

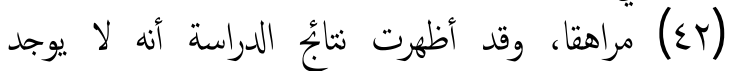

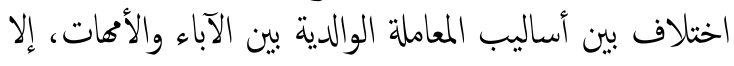

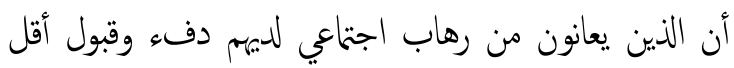

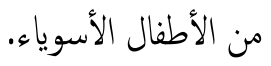

نوعين فرعيبن، يسمى النوع الأول، الرهاب الاجتاعي المعمم

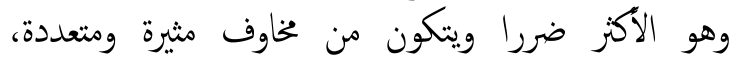

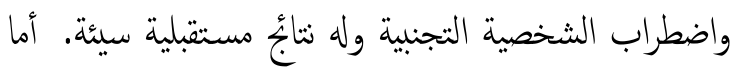

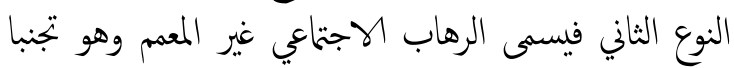

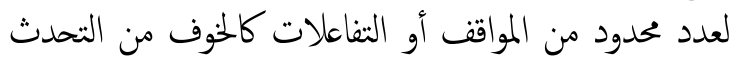

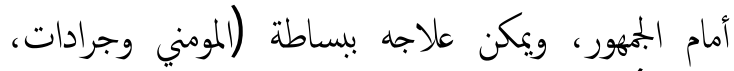
$.(r \cdot))$ وهناك عوامل عديدة مسبة للرهاب الاجتماعي منها الأسباب

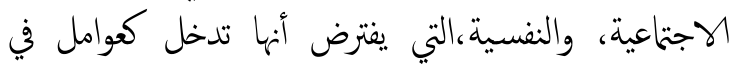

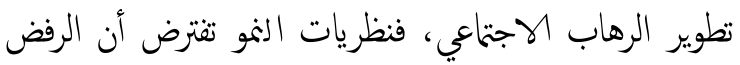

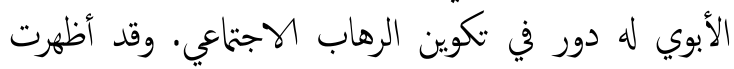

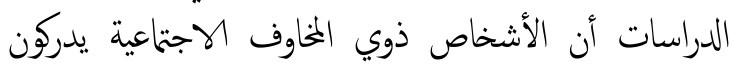

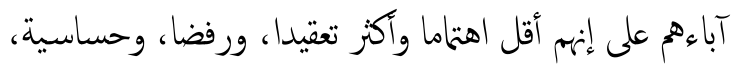

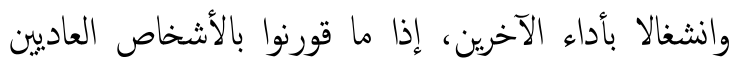

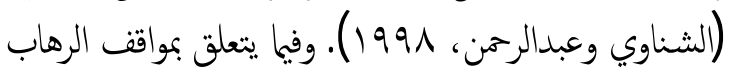
الاجتماعي للأشخاص القلقين اجتاعيا، فإنهم يخبرون عادة ألما انفعاليا في العديد من المواقف الاجتياعية، ومن هذه المواقفي:

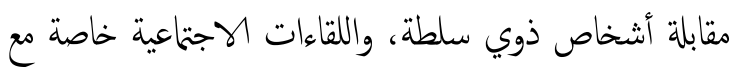

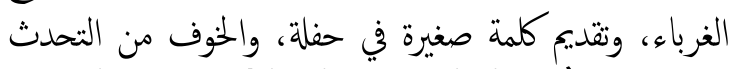

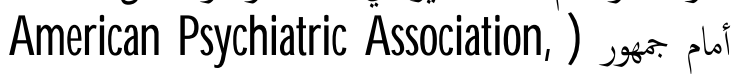

(1994

وتشير الدراسات إلى أن نسبة كيرة من المصابين بالرهاب

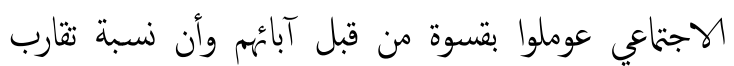

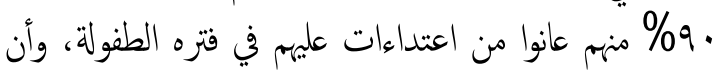

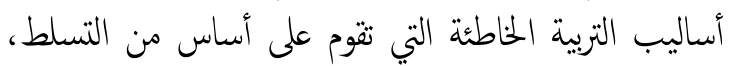

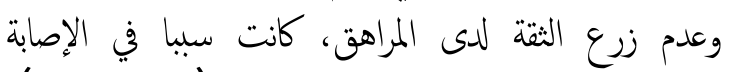
بالرهاب الاجتماعي وتقدير الذات المنخفض (المالح، وتلعب مرحلة المراهقة دورا بارزا في تشكيل الرهاب

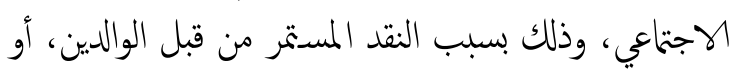

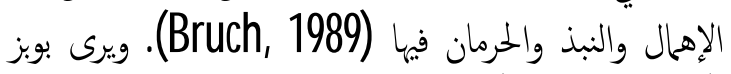
(Bobes, 1999)

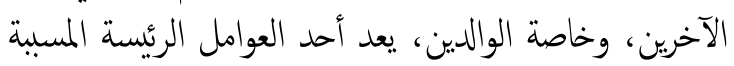

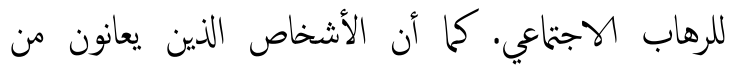
الرهاب الاجتاعي يتمركزون حول ذواتهم، ويخشون الآخرين.

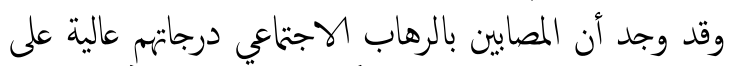
مقياسي العصابية وقلق السمة (Sheehan, 1987). 
أبناء الوالدين المتسلطين والمازمين أكر حزما من أبناء الوالدين

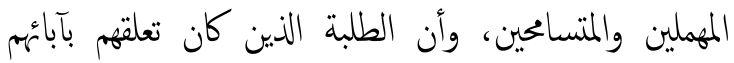
بدرجة متوسطة أكر حزما من أولكك الذين كان تعلقهم بدرجة النمان عالية أو منخفة.

وغنينزيرغ دراسة التي هدفت للكشف عن (Festa \& Ginsburg, 2011)

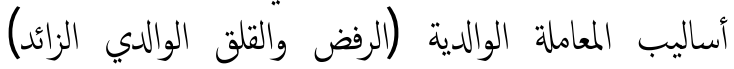

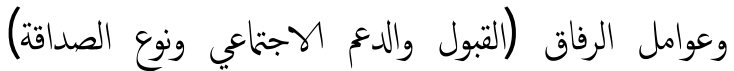

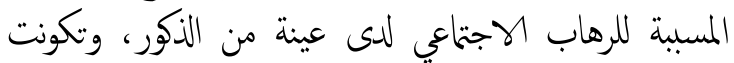

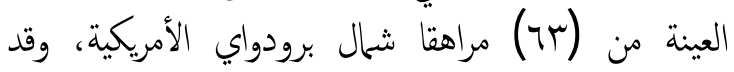

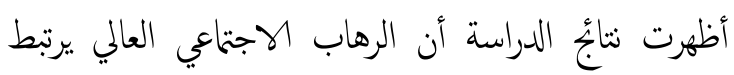

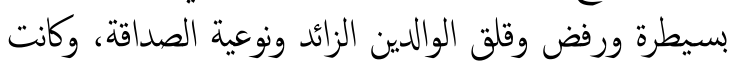
السيطرة الوالدية متنبئ قوي بالرهاب الوالهتئاعي.

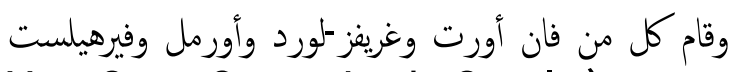

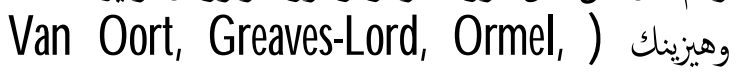
(Verhulst \& Huizink, 2011

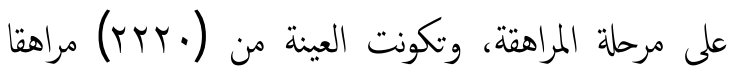

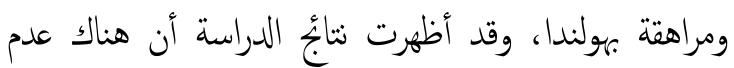

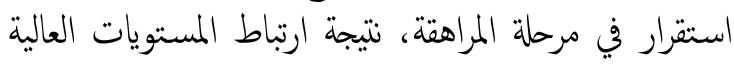

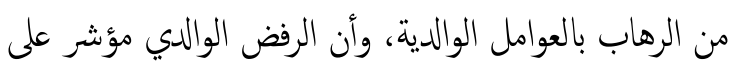
الرهاب في مرحلة المراهتة المبكرة.

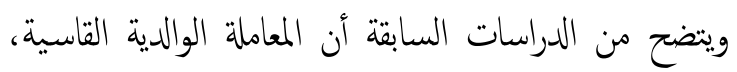

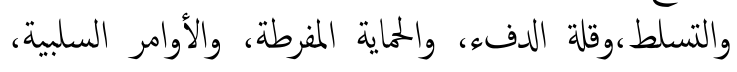

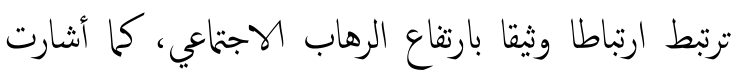
بعض الدراسات إلى أن ارتغاع الرهاب الاجتماعي لدى الإناث

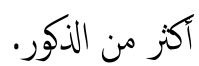

\section{مشكلة الدراسة وأسئلها من المورن}

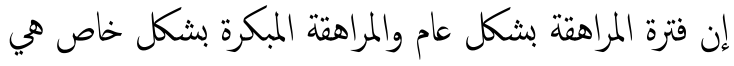

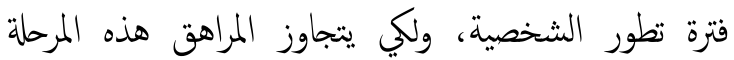
بلام لا بد من تناسق أسري سليم؛ فالأسرة لها الأثر الكبير المارية

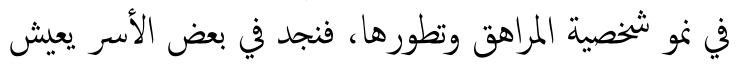

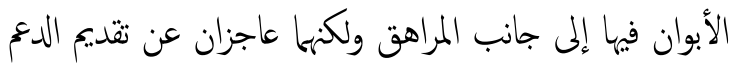

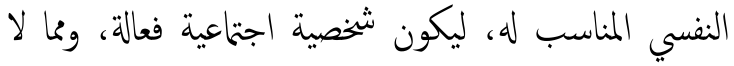

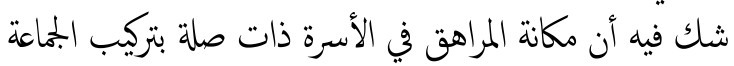

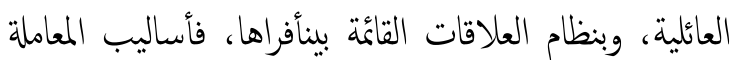

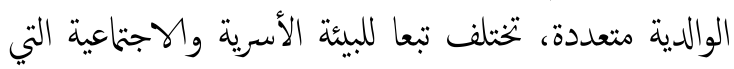

Anhalt \& Morris, ) وهدفت دراسة أنهالت وموريس

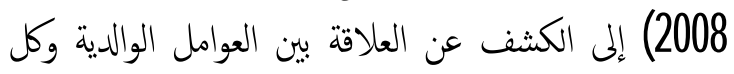

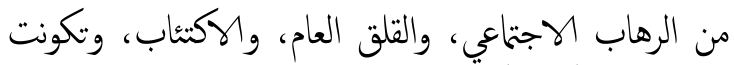

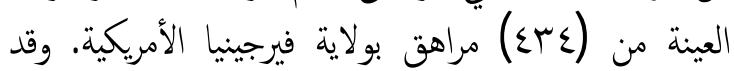

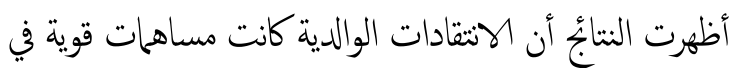

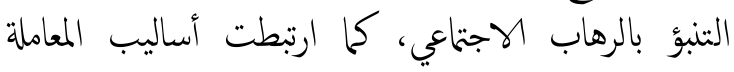

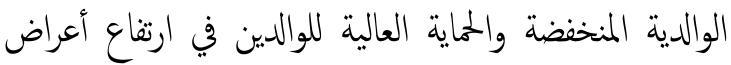

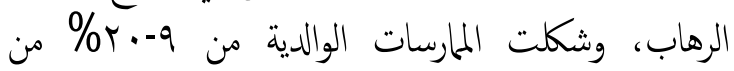

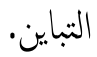
وهدفت دراسة زبيدات وبارا وسيرا وساليناس (Zubeidat, Parra, Sierra \& Salinas, 2008) التعرف على العوامل المرتبطة بالرهاب الإجتاعي،

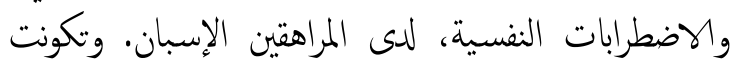

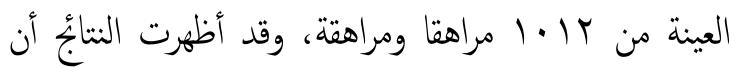

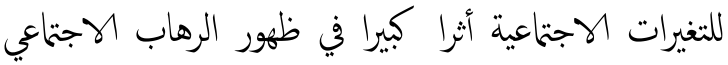

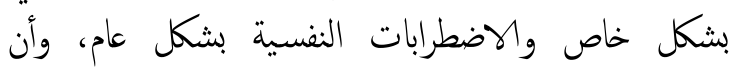
متوسط در جات الإناث أعلى من متوسط درجات النطية الذوكر. وقام لوكاس (Loukas, 2009) بدراسة السطيرة النفسية

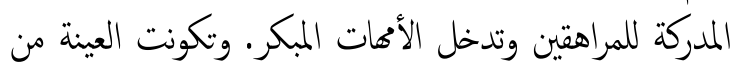

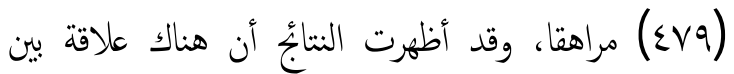

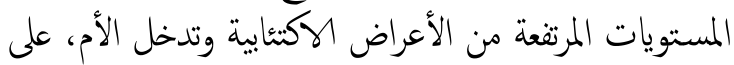

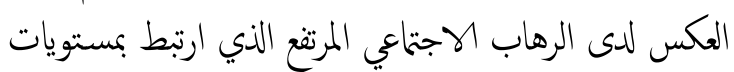

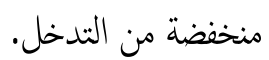
أما دراسة رورك وموريس (Rork \& Morris, 2009) فقد هدفت للتعرف على كل من سلوكات الوالدين والتنشئة،

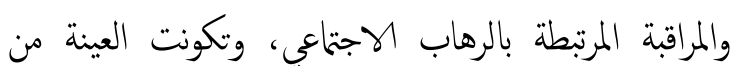

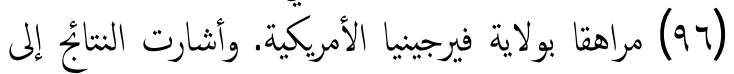

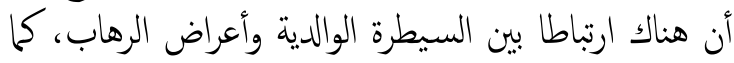

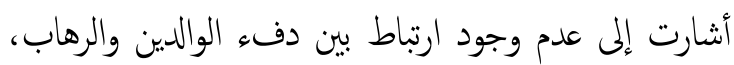

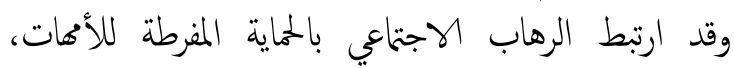

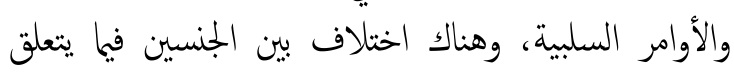
بتأثير سلوكيات الوالدين على المراهق. وتناولت دراسة كل من سنكسفنوكيردوك و وآسيك (Cenkseven, Kirdok \& Isik, 2010)

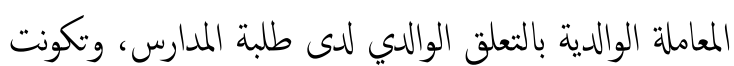

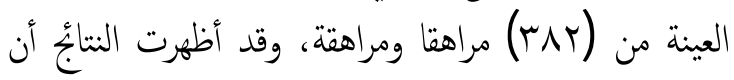


هذه الدراسة بمثابة دعوة إلى توجيه أنظار العاملين في المجالين'

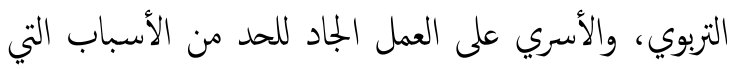

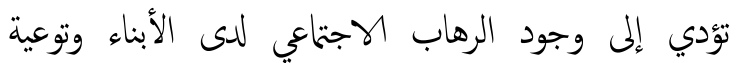

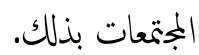

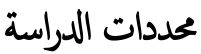

1. اقتصرت الدراسة على طلبة الصفين السابع، والثامن في

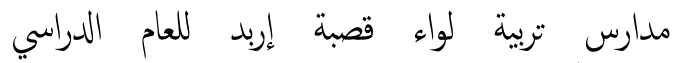
$1 \mathrm{r}+1 T / r \cdot 11$

r. بكثت الدراسة الحالية علاقة أساليب المعاملة الوالدية

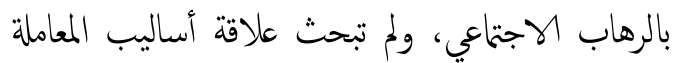

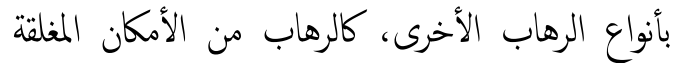

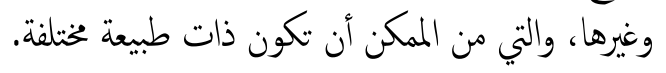

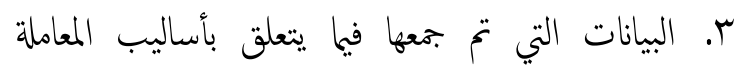
الوالدية كان مصدرها الأبناء الذين في مرحلة المراهقة

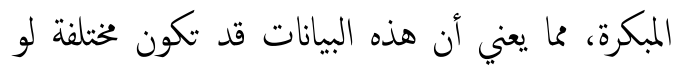
كان مصدرها الآباء أنفسهم.

\section{الطريقة والإجراءات}

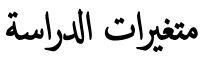

اثتملت هذه الدراسة على المتغيرات الآتية، أساليب المعاملة

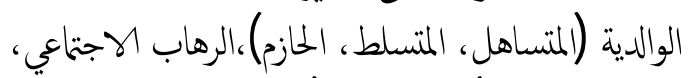

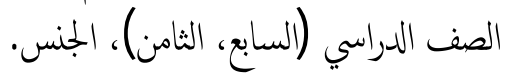

\section{منهج الدراسة}

انتعت الدراسة الحالية المنهج الارتباطي والتنبؤي، إذ أنها

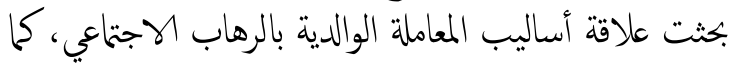

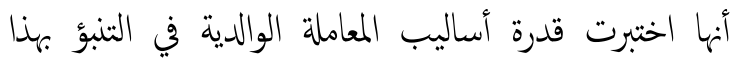

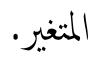

\section{مجتع الدراسة} تكون ججتع الدراسة من جميع طلاب وطالبات الصفين السابع

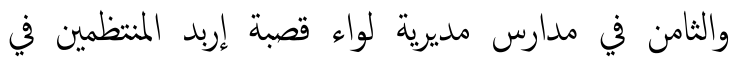

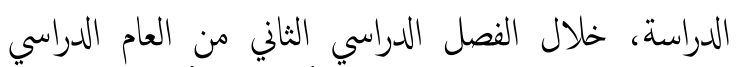

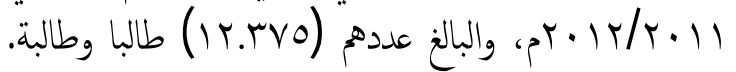

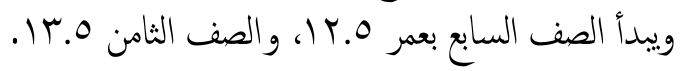

تنتي لها الأسرة، ويحاول الباحثان في هذا البحث إلقاء الضوء

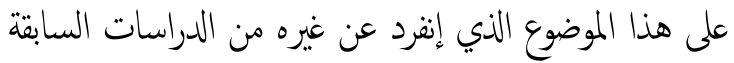
بتناوله استكشاف علاقة أساليب المعاملة الوالدية بالرهاب

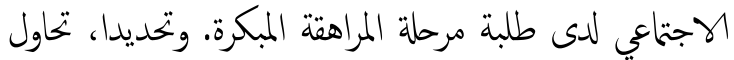
الدراسة الإجابة عن الأسئلة الآتية'. 1. هل توجد فروق ذات دلالة إحصائية (0.,.) في

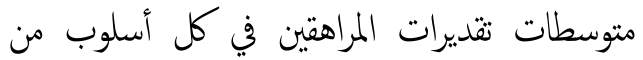
أساليب المعاملة الوالدية (صورة الأب، صورة الأم) تعزى للجنس والمستوى الصفي والتفاعل بينها؟ r. هل توجد فروق ذات دلالة إحصائية (0....) بين متوسطات درجات المراهقين على مقياس الرهاب الاجتماعي تعزى للجنس والمستوى الصفي والتفاعل

بينها؟ r. هل توجد علاقة ذات دلالة إحصائية عند مستوى بلئ

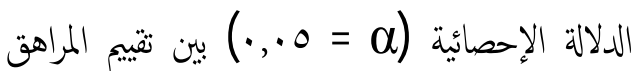
لأسلوب المعاملة الوالدية (الأب، الأم) ومستوى المانية المراهن الرهاب الاجتماعي لديه؟

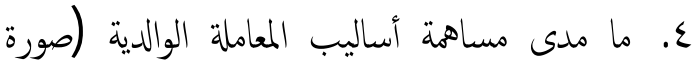

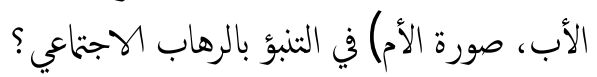

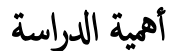

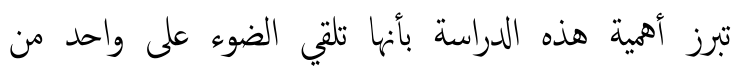

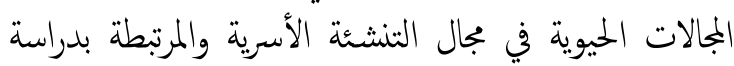

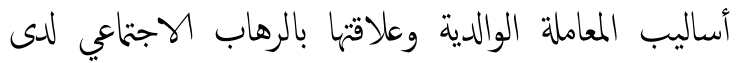

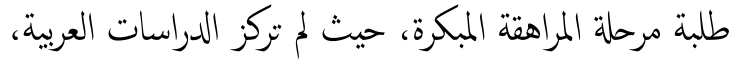
والأجنبيةبشكل خاص على تناول أساليب المعاملة الوالدية

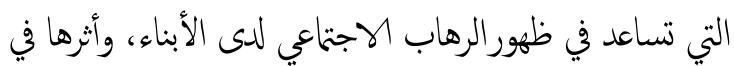
حياته النفسية، وتكوين شخصيته في مرحلة المراهقة المبكرة؛

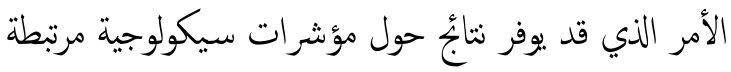

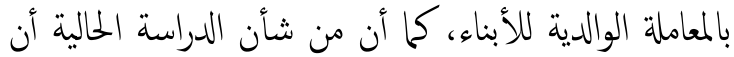

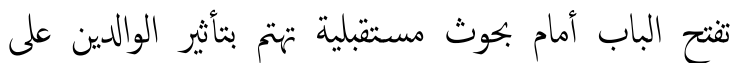
الأبناء وشخصياتهم، إذ إن المعاملة الوالدية المرتبطة بالصحة النفسية، وخاصة الرهاب الاجتماعي لم تحظ باهتمام الباحثين

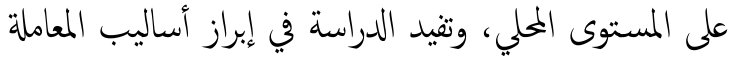

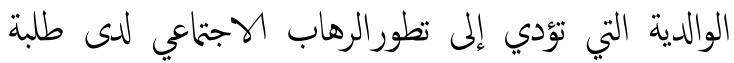

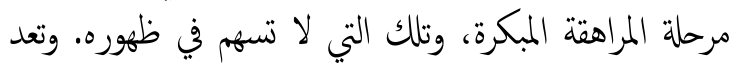


خحاسي يتضمن البدائل: (مطلقا تعطى عند تصحيح المقيـاس

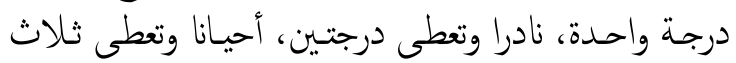

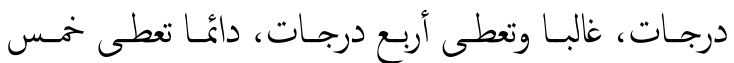

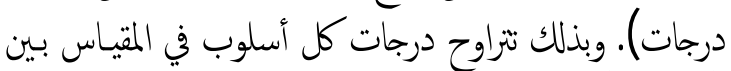

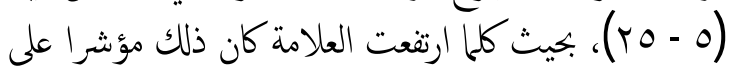

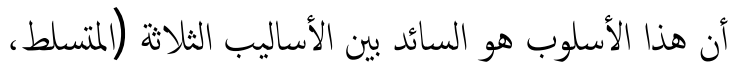
الحازم، المتساهل). - (ان هذا الأوبل

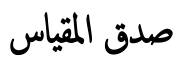

قام جرادات والجوارنة (مقبول للنشر) بتطبيق النسخة

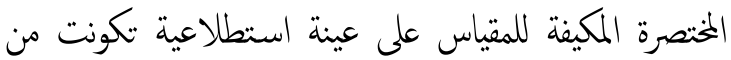
(VT)

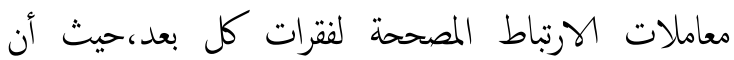

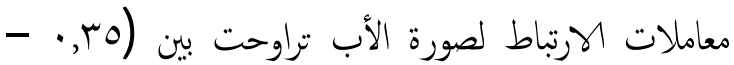

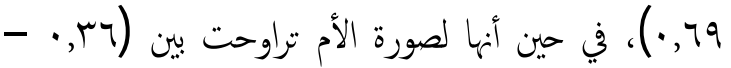

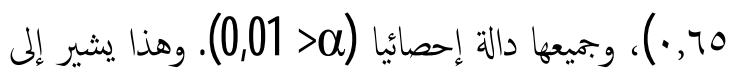
أن الصورة الختصرة للمقياس تتمتع بصدق بناء جيد. وفي الدراسة الحالية، طبقت النسخة المختصرة المكيفة

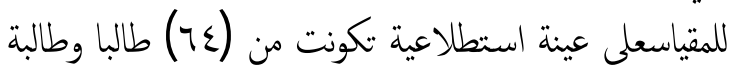

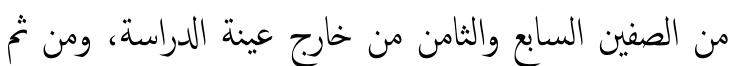

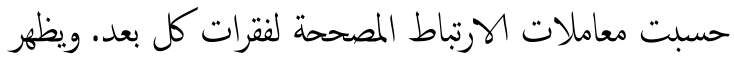

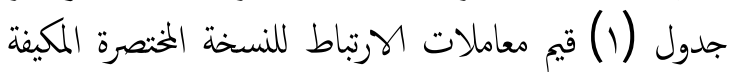

$$
\text { لمقياس أساليب المعاملة الوالدية. }
$$

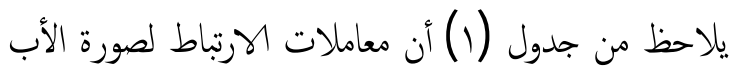

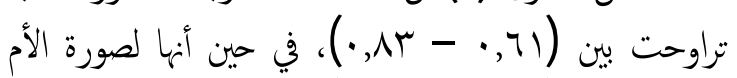

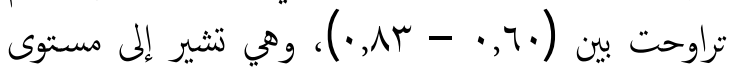
مرتفع من صدق البناء للأداة.
عينة الدراسة

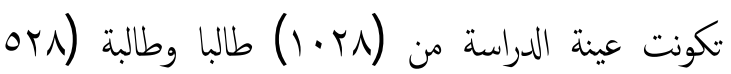

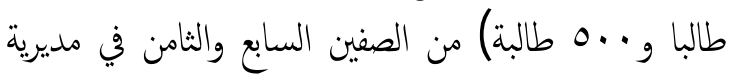
التربية والتعليم للواء قصبة إربد اختيروا بالطريقة العشوائية

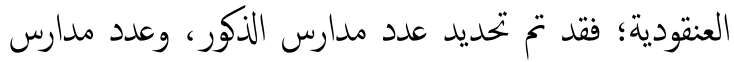

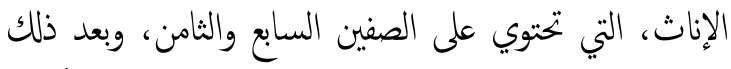

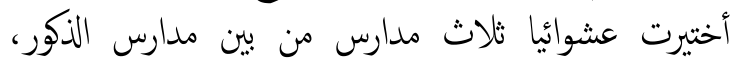

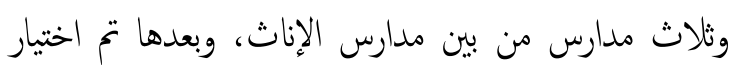
جميع الطلبة في هذين الصفين من كل مدرسة من من المدارس

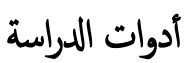

أولاا مقياس أساليب المعاملة الوالدية' تم استخدام الصورة

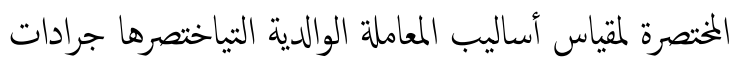

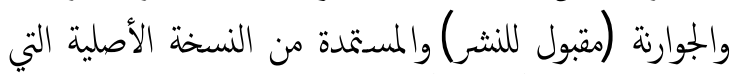

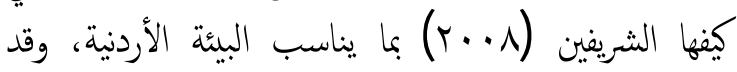

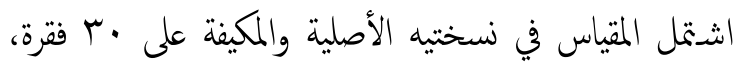

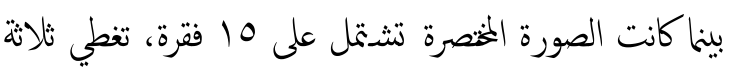

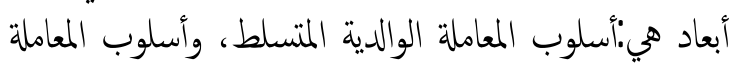

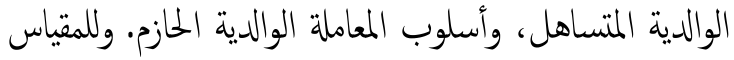

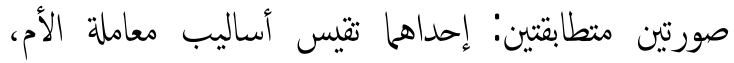
والأخرى تقيس أساليب معاملة الأب، وذلك كما يدركها الأبناء

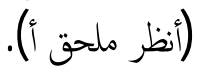
تصحيح المقياس'

اشـتملت الصـورة المختصرة المكيفة لمقيـاس أسـاليب المعاملة

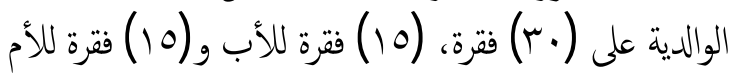

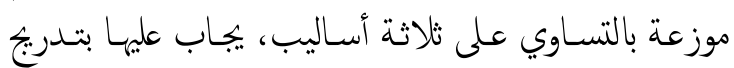

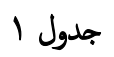

معاملات الارتباط المصحمة لفقرات مقياس أساليب المعاملة الوالدية بصورتيه (الأب، الأم) مع أبعادها

\begin{tabular}{|c|c|c|c|c|c|c|c|c|}
\hline \multicolumn{2}{|c|}{ (معامل البرتباط المصحح) } & \multirow[t]{2}{*}{ الفقرة } & \multicolumn{2}{|c|}{ (معامل الارتباط المصحح) } & \multirow[t]{2}{*}{ الفقرة } & \multicolumn{2}{|c|}{ 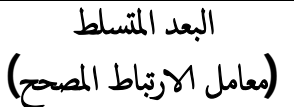 } & \multirow[t]{2}{*}{ الفقرة } \\
\hline الأم & الأب & & الأم & الأب & & الأم & الأب & \\
\hline$\cdot, V r$ & $\cdot, V 1$ & 11 & $\cdot, \vee \wedge$ & $\cdot, \Lambda \cdot$ & 7 & $\cdot, V T$ & $\cdot, 199$ & 1 \\
\hline ז & • & $1 \pi$ & $\cdot, \Lambda \cdot$ & $\cdot, \lambda)$ & V & $\cdot, 77$ & $\cdot, V \cdot$ & $r$ \\
\hline$\cdot, V V$ & • & $1 \pi$ & $\cdot, \top \Lambda$ & $\cdot, V r$ & $\wedge$ & س & $\cdot, 71$ & $r$ \\
\hline r, & • & $1 \varepsilon$ & . & r & 9 & . & $\cdot \pi, \pi$ & $\varepsilon$ \\
\hline$\cdot$, AT & $\cdot, V V$ & 10 & T & $\cdot, V T$ & 1. & $\cdot, V \varepsilon$ & $\cdot, 77$ & 0 \\
\hline
\end{tabular}


الوالدية على عينة الدراسة الحالية والمكونة من ^ץ •ا طالبا

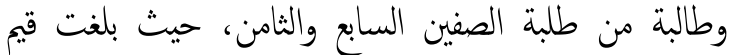

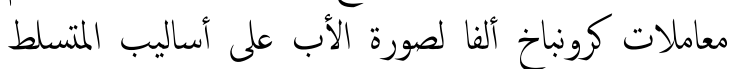

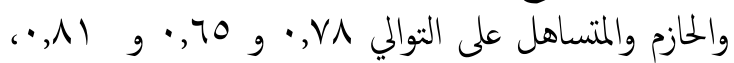

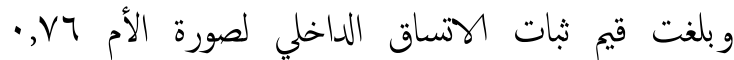

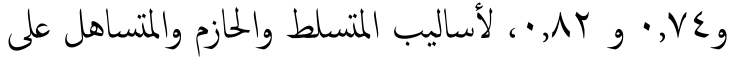

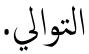

ثانيا': مقياس الرهاب الاجتثاعي' تم استخدام مقياس الرهاب الاجتاعي لمانيك وكلارك (Mattick \& Clark, 1998)

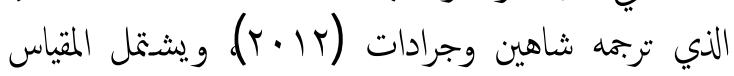

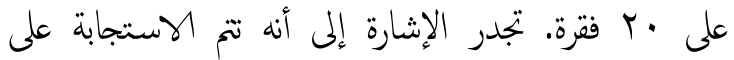

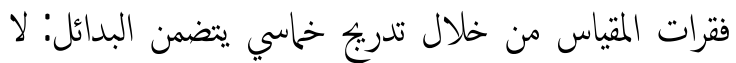
تنطبق على الإطلاق وتعطى صفرا، وتنطبق بدرجة منخفضة

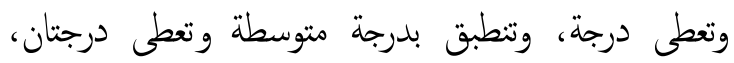

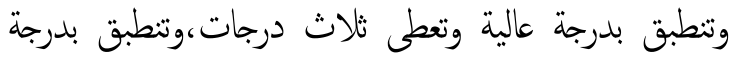

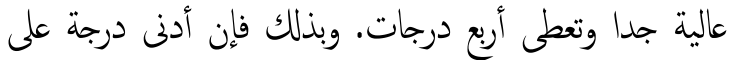

$$
\text { المقياس هي صفر وأعلى درجة هي ·يد. }
$$

صدق البناءi' لاستخراج دلالات صدق البناء، قام شاهين

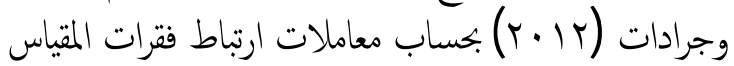

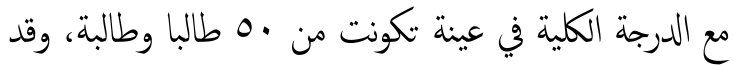

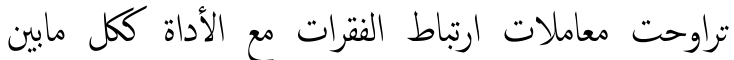

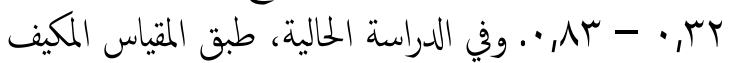

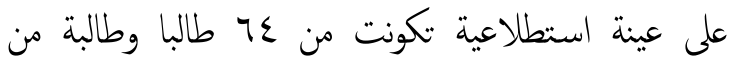

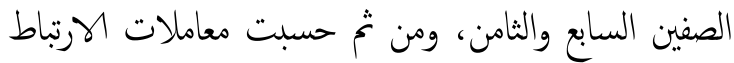

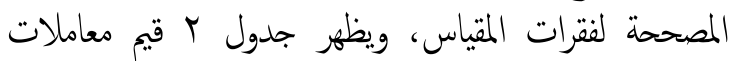

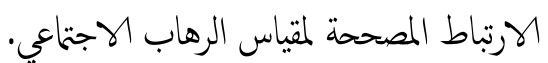

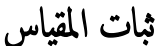

قام جرادات والجوارنة (مقبول للنشر) بتقدير ثبات الاتساق الداخلي النسخة المختصرة لمقياس أساليب المعاملة الوالدية

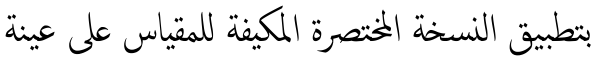

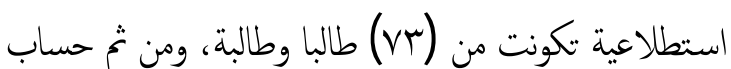
معاملات ثبات الاتساق الداخلي باستخدام معادلة كرونباخ

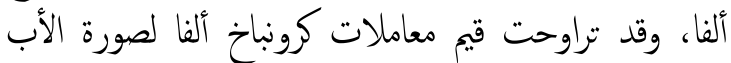

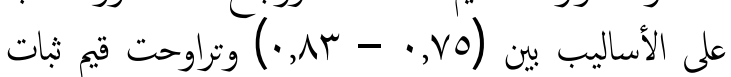

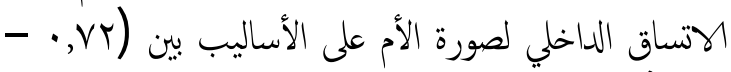

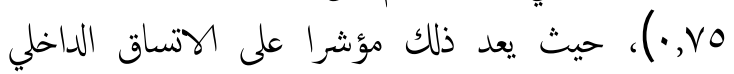

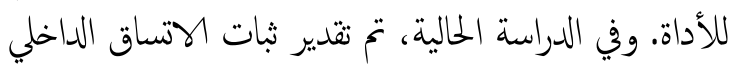
للنسخة الخختصرة المكيفة لمقياس أساليب المعاملة الوالدية

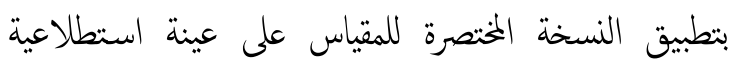

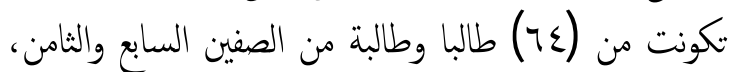
وحساب معاملات الثبات باستخدام معادلة كرونباخ ألفا،

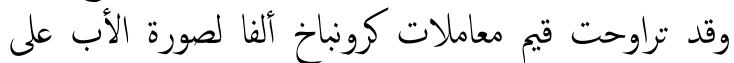

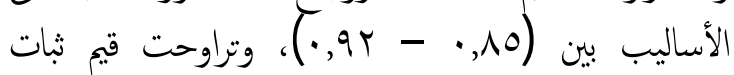

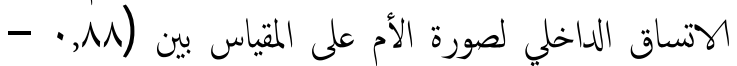

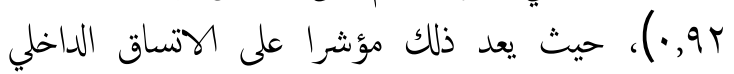

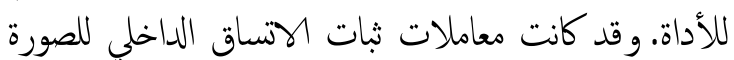

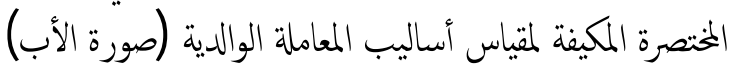

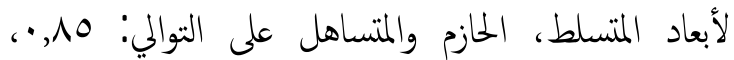

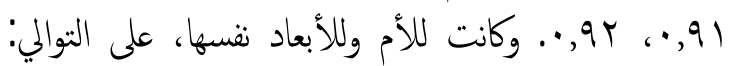

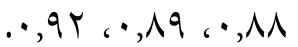

كما تم التحقق من ثبات الاتساق الداخلي باستخدام معادلة

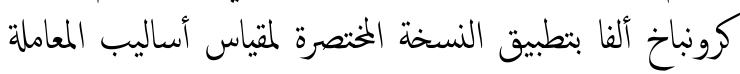

جدول

\begin{tabular}{|c|c|c|c|c|c|}
\hline 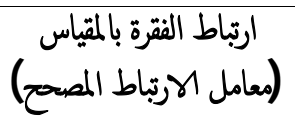 & الفترة & 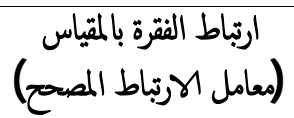 & الفقرة & 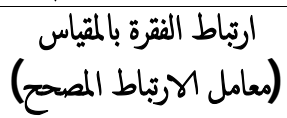 & رالفرة \\
\hline$\cdot, \mathrm{Nr}$ & 10 & $\cdot, 01$ & $\wedge$ & $\cdot, 70$ & 1 \\
\hline$\cdot, 00$ & 17 & $\cdot, 71$ & 9 & $\cdot, 09$ & $r$ \\
\hline$\cdot, \mathrm{VA}$ & IV & •, & 1. & זד, & $r$ \\
\hline$\cdot, 94$ & 11 & $\cdot, 10$ & 11 & $\cdot, V \varepsilon$ & $\varepsilon$ \\
\hline$\cdot, \lambda r$ & 19 & $\cdot, 19$ & IT & $\cdot, 199$ & 0 \\
\hline$\cdot{ }^{\prime}, r \mu$ & $r \cdot$ & • & $1 T$ & , , & 7 \\
\hline & & $\cdot, \vee \wedge$ & $1 \varepsilon$ & $\cdot, 91$ & $v$ \\
\hline
\end{tabular}

قيم معاملات الارتباط المصحة لفقرات مقياس الرهاب الاجتاعي 
على الطلبة داخل الغرف الصفية ووضحت التعليمات المتعلقة

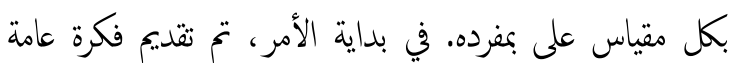
للطلبة عن أهداف الدراسة وأهيتها وتح التأكيد لمم أن مشاركهم طوعية، وأن البيانات التي سيدلون بها ستعامل بسرية تامة إنها.

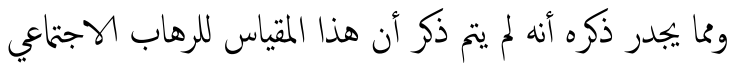

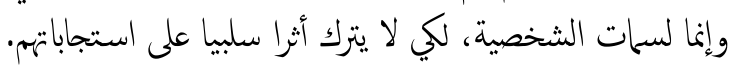

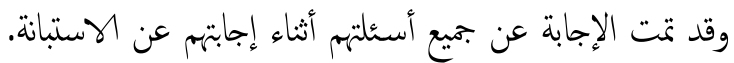

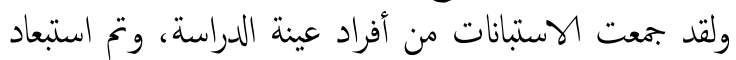

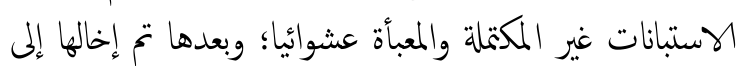

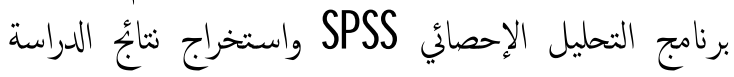
الحالية.

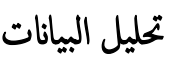

تم حساب المتوسطات الحسابية والانحرافات المعيارية لدرجات

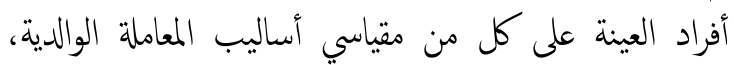

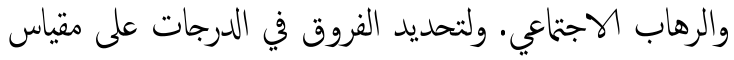

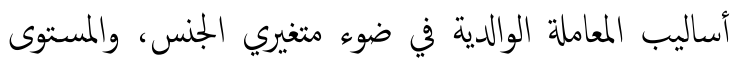

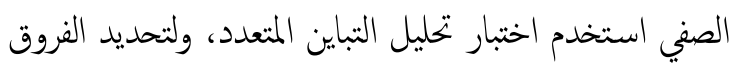

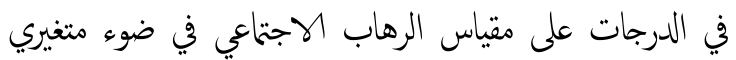
الجنس والمستوى الصفي استخدم اختبار تحليل التباين الثنائي.

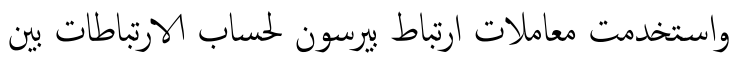
درجات أفراد العينة على مقياس أساليب المعاملة الوالدية الماتية

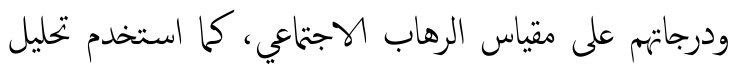

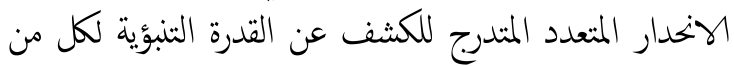

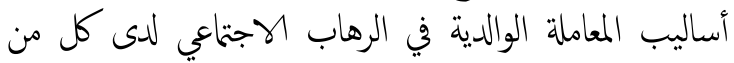
الجنسين ولكل من المستويين الصفيين.

\section{النتائج}

فيها يـلي سـيتم عرض النتـائح المتعلقة بالأسـئلة التي حاولت

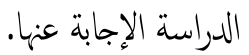

السؤال الأول: هل توجد فروق ذات دلالة إحصائية (ه..,·)

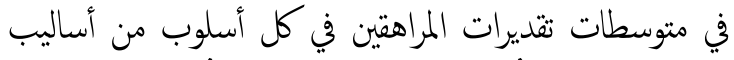

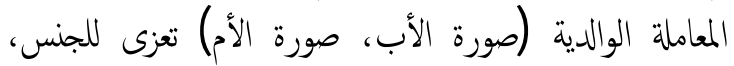

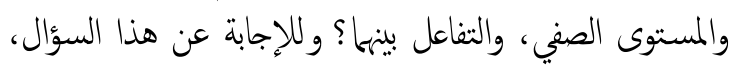
حسبت المتوسطات، والانحرافات المعيارية لدرجات المراهقين

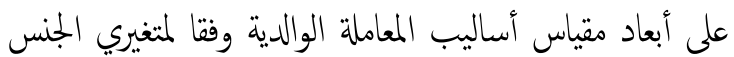

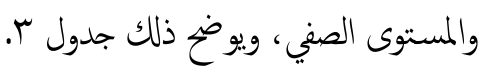

يلاحظ من جدول r أن معاملات الارتباط المصححة لفقرات

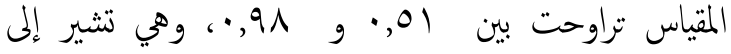
مستوى مرتغع من صدق البناء للأداة.

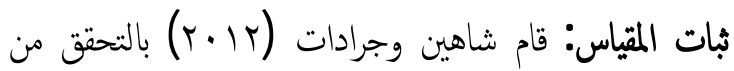

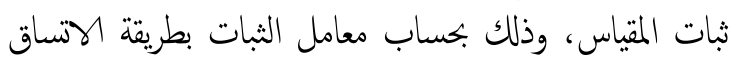

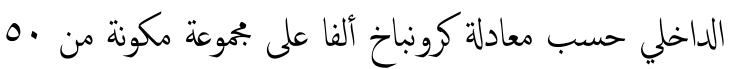

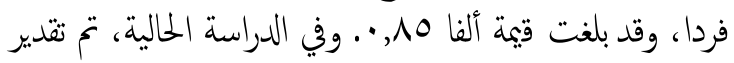
ثبات الاتساق الداخلي للمقياس بتطبيقه على عينة استطلاعية

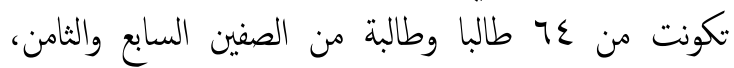

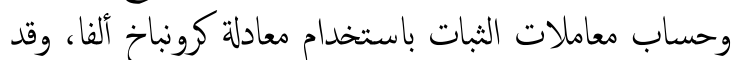

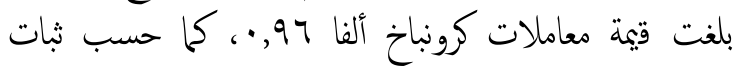

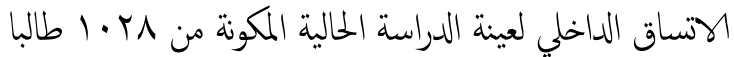

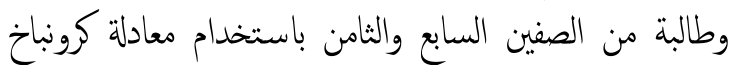

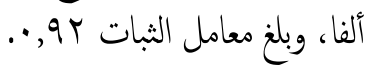

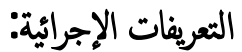

أساليب المعاملة الوالدية' الطريقة التي يعامل به الوالدان ابنها

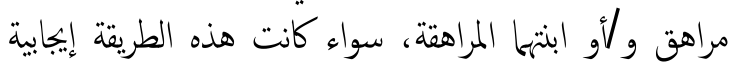

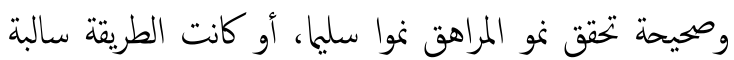

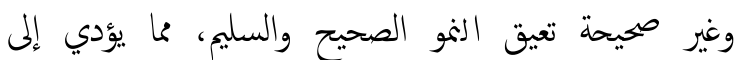

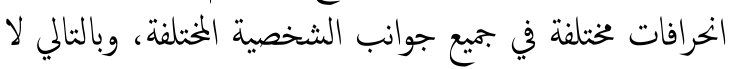
يحقق التوافق النفسي والاجتماعي. ويعرف إجرائيا من خلال

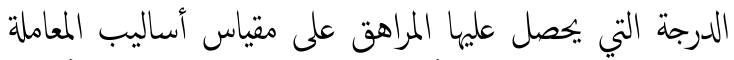

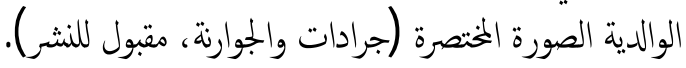
الرهاب الاجتاعي: هو أحد أكثر الاضطرابات شيوعا، ويتميز

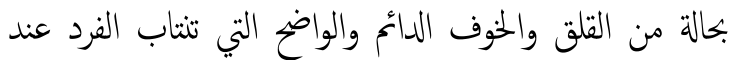

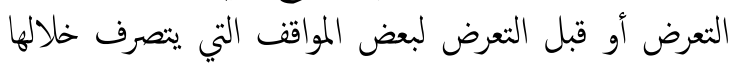
بطريقة محرجة لأنه محط أنظار الآخرين، وتم تعرفه إجرائيا من المان خلال درجة القطع التي حصل عليها المراهق على مقياس الرهاب الرهاب

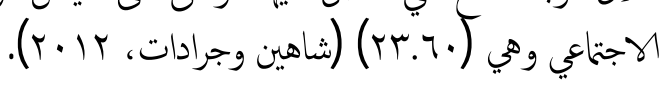
المراهقة المبكرة' ويقصد بها المرحلة العمرية التي يقع بها طلبة

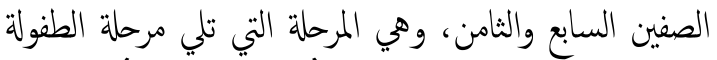

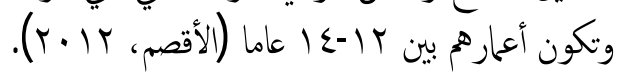

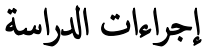

تم التطبيق على عينة استطلاعية من طلبة الصفين السابع

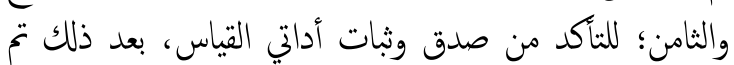
تحديد المدارس المراد تطبيق المستبانة عليها،وزعت الهن الهستبانة 


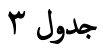

المتوسطات الحسابية والانحرافات المعيارية لدرجات المراهقين على أبعاد مقياس أساليب المعاملة الوالدية

\begin{tabular}{|c|c|c|c|c|c|}
\hline \multirow{2}{*}{ المتوسط الكلي } & \multirow[t]{2}{*}{ 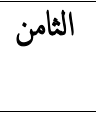 } & \multirow[t]{2}{*}{ السابع } & & \multirow{2}{*}{ المستوى الصفي } & \multirow{2}{*}{ أساليب المعاملة } \\
\hline & & & & & \\
\hline$r, 17$ & $r, \cdot r$ & $r, Y T$ & س & الذكور & \\
\hline$\cdot, \wedge 0$ & $\cdot, \wedge \varepsilon$ & • & $\varepsilon$ & & \\
\hline$r, 9 \varepsilon$ & $r, I r$ & $r, 70$ & 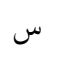 & الإناث & أسلوب المعاملة المتسلط للأب \\
\hline $1, \cdot 1$ & $\cdot, 90$ & $1, \cdot r$ & $\varepsilon$ & & \\
\hline$r, \cdot 0$ & $r, \wedge$ & $r, \cdot r$ & س & العينة كلل & \\
\hline$\cdot, q$ & $\cdot, 91$ & $\cdot, 97$ & $\varepsilon$ & & \\
\hline$r, \Lambda \Lambda$ & $r, 90$ & $\Gamma, \Lambda)$ & س س & 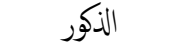 & \\
\hline$\cdot, \mathrm{VO}$ & $\cdot, V V$ & $\cdot, \mathrm{V}$ & $\varepsilon$ & & \\
\hline$r, q 1$ & r,入 $\varepsilon$ & $\varepsilon, \cdot r$ & 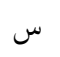 & الإناث & أسلوب المعاملة الحازم للأب \\
\hline$\cdot, 77$ & ( & $\cdot, 79$ & $\varepsilon$ & & \\
\hline r,人 & r,人 & r,人 & 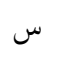 & العينة كلل & \\
\hline$\cdot, \times 1$ & $\cdot, \mathrm{V} \cdot$ & $\cdot, V T$ & $\varepsilon$ & & \\
\hline$r, 70$ & $r, \uparrow q$ & $r, \wedge V$ & س & 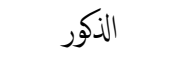 & \\
\hline $1, \cdot 7$ & $1, \cdot 1$ & $1, \cdot 0$ & $\varepsilon$ & & \\
\hline$T, V T$ & r,99 & $r, r \wedge$ & 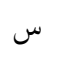 & الإناث & أسلوب المعاملة المتساه لللأب \\
\hline $1, r \cdot$ & 1,17 & $1,1 \varepsilon$ & $\varepsilon$ & & \\
\hline$r, 79$ & $r, V T$ & $T, 7 \varepsilon$ & 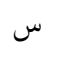 & العينة كلل & \\
\hline 1,11 & $1,1 \varepsilon$ & $1,1 \mathrm{~T}$ & $\varepsilon$ & & \\
\hline r,IT & $r, 97$ & r, ro & 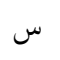 & 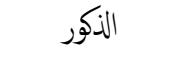 & \\
\hline$\cdot, \wedge 9$ & $\cdot, 10$ & $\cdot, 91$ & $\varepsilon$ & & \\
\hline$r, \cdot 1$ & $r, 17$ & $r, V T$ & 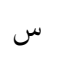 & الإناث & أسلوب المعاملة المتسلط للأم \\
\hline $1, \cdots$ & $\cdot, q 4$ & $1, \cdot 0$ & $\varepsilon$ & & \\
\hline$r, \cdot v$ & $r, \cdot \Lambda$ & $r, \cdot \tau$ & 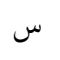 & العينة كلك & \\
\hline$\cdot, 90$ & $\cdot, 9$ & $1, \cdots$ & $\varepsilon$ & & \\
\hline$r, v q$ & $r, \lambda r$ & $r, v V$ & 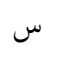 & 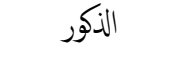 & \\
\hline$\cdot, \Lambda$ & $\cdot, 9$ & $\cdot, \mathrm{VV}$ & $\varepsilon$ & & \\
\hline$r, q \varepsilon$ & 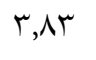 & $\varepsilon, 11$ & 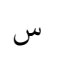 & الإناث & أسلوب المعاملة الحازم للأم \\
\hline$\cdot, \mathrm{V} \varepsilon$ & $\cdot, \mathrm{VO}$ & $\cdot, \mathrm{V} \cdot$ & $\varepsilon$ & & \\
\hline ґ,人 & r,人 & $r, q$. & 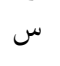 & العينة كلل & \\
\hline$\cdot, \vee 9$ & $\cdot$, At & $\cdot, \vee Y$ & $\varepsilon$ & & \\
\hline T,N & r,OV & $r, \cdot o$ & 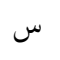 & 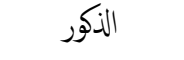 & \\
\hline 1,1 & $1, \cdot 7$ & $1, \cdot 1$ & $\varepsilon$ & & \\
\hline$r, v r$ & $r, \cdot 1$ & $T, T V$ & 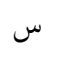 & الإناث & أسلوب المعاملة المتساه لللأم \\
\hline $1, Y_{0}$ & $1, r$ & $1, r$ & $\varepsilon$ & & \\
\hline r, VA & r,A & $r, V \varepsilon$ & 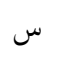 & العينة كلل & \\
\hline 1,11 & 1,17 & 1,19 & $\varepsilon$ & & \\
\hline
\end{tabular}




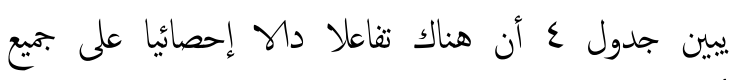
أساليب المعاملة الوالدية.

السؤال الثانيi هل توجد فروق ذات دلالة إحصائية

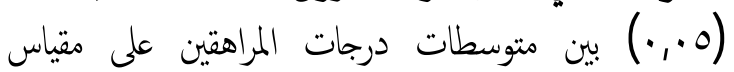
الرهاب الاجتماعي تعزى للجنس، والمستوى الصفي، والثفاعل المران

بينها ك.
يبين جدول r و وجود فروق ظاهرية بين المتوسطات الحسابية

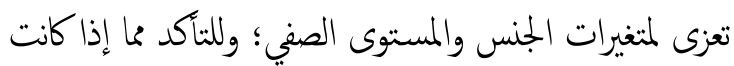

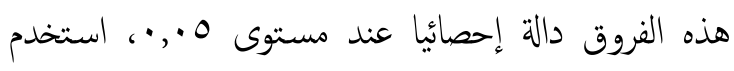

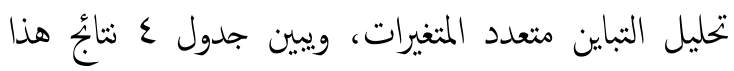

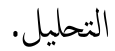

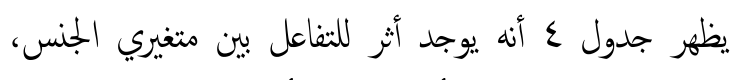
والمستوى الصفي، على أبعاد مقياس أساليب المعاملة الوالدية، المئ،

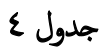

تتابُ تحليل التباين متعدد المتغيرات لاستجابات أفراد عينة الدراسة على مقياس أساليب المعاملة الوالدية حسب متغيرات الدراسة

\begin{tabular}{|c|c|c|c|c|c|}
\hline قيمة ف & متوسط المربعات & الحرية & المربعات & المتغيرات التابعة & مصدر التباين \\
\hline 秋, $\cdot, 71$ & $|V, I|$ & 1 & $|V| \mid$, & أسلوب المعاملة المتسلط للأب & \\
\hline $1, \cdot 9$ & $\cdot, 00$ & 1 & $\cdot, 00$ & أسلوب المعاملة الحازم للأب & \\
\hline$\cdot, \cdots$ & $\varepsilon, \pi$ & 1 & $\varepsilon, \pi$ & أسلوب المعاملة المتساهل للأب & الجنس الجن \\
\hline$*_{0, \lambda r}$ & $0, \cdot 0$ & 1 & $0, \cdot 0$ & أسلوب المعاملة المتسلط للأم & \\
\hline 快, & $\Lambda_{1} \cdot \varepsilon$ & 1 & $\Lambda_{1} \cdot \varepsilon$ & أسلوب المعاملة الحازم للأم & \\
\hline * & $7, \wedge \wedge$ & 1 & $7, \wedge \wedge$ & أسلوب المعاملة المتساهل للأم & \\
\hline$* \varepsilon, \mid V$ & $r, \Sigma T$ & 1 & $r, \varepsilon \tau$ & أسلوب المعاملة المتسلط للأب & \\
\hline$\cdot, 17$ & $\Lambda_{1} \cdot r$ & 1 & $\Lambda_{1} \cdot r$ & أسلوب المعاملة الحازم للأب & \\
\hline$r, Y)$ & r, ro & 1 & r, ro & أسلوب المعاملة المتساهل للأب & المستوى الصفي \\
\hline$\cdot, \wedge 7$ & $\cdot$, Vo & 1 & $\cdot$, vo & أسلوب المعاملة المتسلط للأم & \\
\hline$*_{0, \text { rt }}$ & $r, r \uparrow$ & 1 & $r, Y \uparrow$ & أسلوب المعاملة الحازم للأم & \\
\hline$r, r \Lambda$ & $\varepsilon, r \mu$ & 1 & $\varepsilon, r \mu$ & أسلوب المعاملة المتساهل للأم & \\
\hline$* * 4, .0$ & $r q, q r$ & 1 & $r q, q r$ & أسلوب المعاملة المتسلط للأب & \\
\hline **I, I, rV & 7,17 & 1 & 7,17 & أسلوب المعاملة الحازم للأب & الجنس الجن \\
\hline$*^{*} v r, 19$ & $\wedge \mathrm{V}, 00$ & 1 & $\wedge V, 00$ & أسلوب المعاملة المتساهل للأب & $X$ \\
\hline 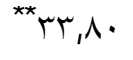 & $r q, r \wedge$ & 1 & $r 9, r \wedge$ & أسلوب المعاملة المتسلط للأم & المستوى الصفي \\
\hline **1,, 9 . & $7,7 V$ & 1 & $7, T V$ & أسلوب المعاملة الحازم للأم & \\
\hline$W^{*} v_{1, \pi}$ & 91,99 & 1 & 91,99 & ه ., •. ، ** دال عند المعاملة المتساهل للأم & 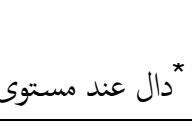 \\
\hline
\end{tabular}

\section{جدول}

\begin{tabular}{|c|c|c|c|c|c|}
\hline \multirow[t]{2}{*}{ تمتاعي } & \multirow[t]{2}{*}{ الثامن } & \multirow[t]{2}{*}{ السابع } & راد & المستتوى الصفي & \multirow[t]{2}{*}{ المقياس } \\
\hline & & & & الجنس & \\
\hline 1,10 & 1,07 & $T_{1} \cdot \Lambda$ & س & الذكور & \\
\hline$\cdot, 9 \vee$ & $\cdot, 19$ & $\cdot, 9 \vee$ & $\varepsilon$ & & \\
\hline$r_{1} \cdot \wedge$ & 5,19 & $1,9$. & س - س & الإناث & الرهاب الاجتماعي \\
\hline$\cdot, \Lambda \Lambda$ & $\cdot, \wedge \varepsilon$ & $\cdot, 94$ & $\varepsilon$ & & \\
\hline 1,97 & 1,94 & $r_{1} \cdot 1$ & س - س & العينة كلل & \\
\hline$\cdot, 9 r$ & $\cdot, 91$ & $\cdot, 90$ & $\varepsilon$ & & \\
\hline
\end{tabular}


الارتباط بين الرهاب الاجتمعي وأساليب المعاملة الوالدية.

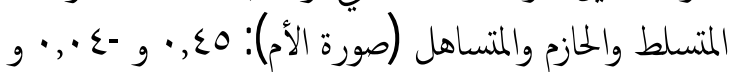

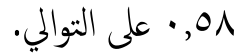

يظهر من معاملات الارتباط أن هناك علاقة إيجابية دالة إحصائيا بين تقديرات أفراد عينة الدراسة على أسلوبي المعاملة:'

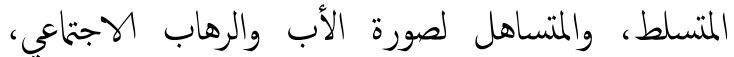

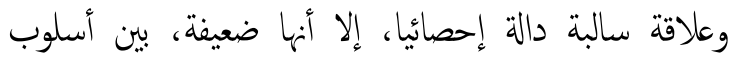

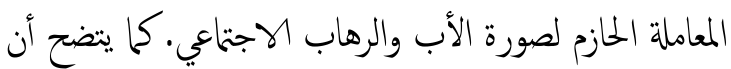
هناك علاقة إيجابية دالة إحصائيا بين أسلوبي المعاملة: الماتئ

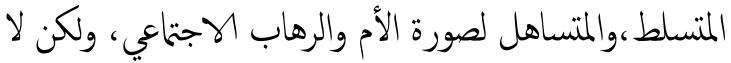

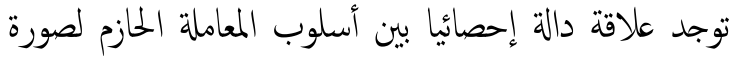

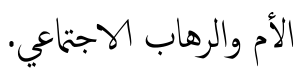
السؤال الرابع' ما مدى مساهمة أساليب المعاملة الوالدية

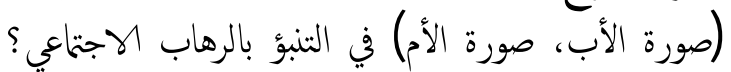

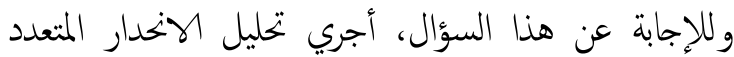

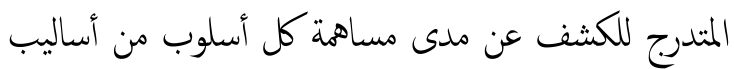

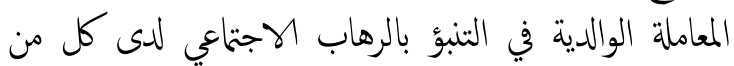

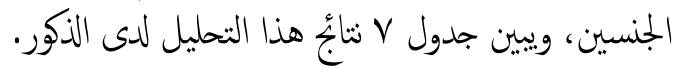
يظهر جدول V أن أسلوبي المعاملة الوالدية المتساهل لصورة

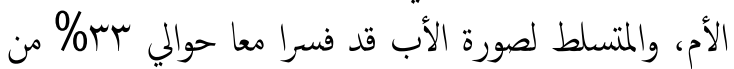

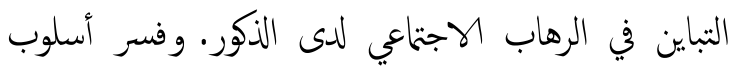

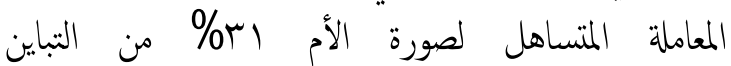

وولمعرفة ما إذاكان هناك فروق بين الجنسين، وبين المستويين الصفيين على مقياس الرهاب الاجتماعي،حسبت المتوسطات

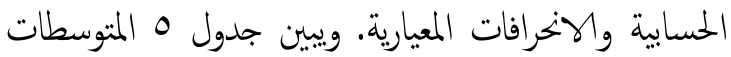
والانحرافات المعيارية لدرجات أفراد العينة على أبعاد مقياس المعاس الماتول

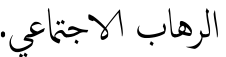
يبين جدول ه وجود فروق ظاهرية في المتوسطات الحسابية

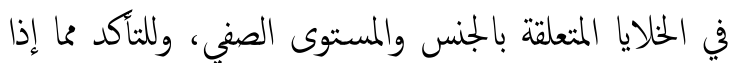
كانت هذه الفروق دالة إحصائيا عند مستوى 0 ×.,•،

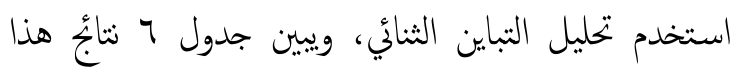

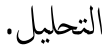

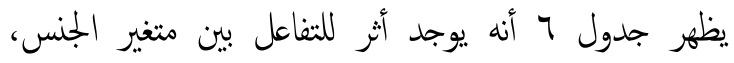

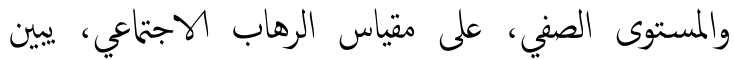

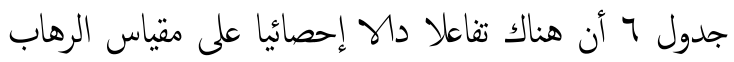
الاجتماعي.

السؤال الثالث' هل توجد علاقة ذات دلالة إحصائية عند

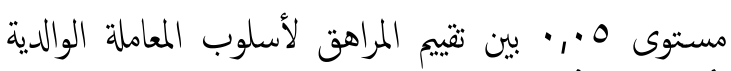

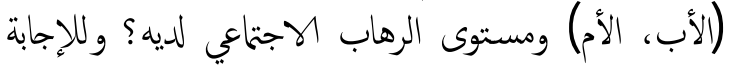

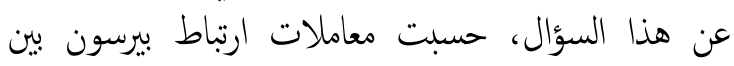

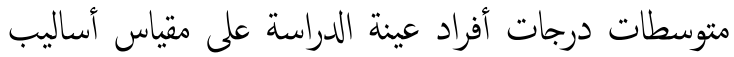
المعاملة الوالدية، ومتوسطات درجاتهم على مقياس الرهاب

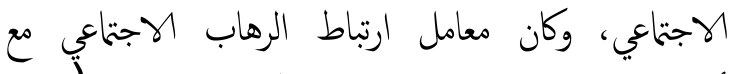

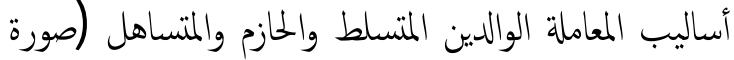

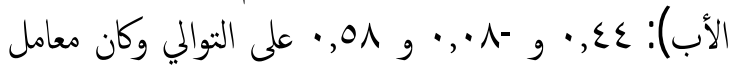

\section{7 جدول 7}

تنائُ تحليل الثباين الثنائي لاستجابات أفراد عينة الدراسة على مقياس الرهاب الاجتاعي وحسب متغيرات الدراسة

\begin{tabular}{|c|c|c|c|c|c|}
\hline قيمة ف & متوسط المربعات & درجات & المربعوت & المتغيرات التابعة & مصدر التباين \\
\hline $10,0 \varepsilon$ & $T, T V$ & 1 & $M T, T V$ & الرهاب الاجتماعي & الجنس \\
\hline$\{, 17$ & $r, r q$ & 1 & $r, r q$ & الرهاب الاجتماعي & المستوى الصفي \\
\hline $0 ., 19$ & $\varepsilon 1, \cdot 1$ & 1 & $\varepsilon 1, \cdot 1$ & الرهاب الاجتمعي & الجنس X المستوى الصفي \\
\hline
\end{tabular}

\section{جدول}

تتابج تحليل الونحدار المتعدد المثدرج لكل أسلوب من أساليب المعاملة الوالدية في التنبؤ بالرهاب الاجتاعي لدى الذكور

\begin{tabular}{|c|c|c|c|c|c|}
\hline قيمة ف & المفر & المتبتداط & معامل الانحدار & المتنبئات & المتغير التابع \\
\hline הTr,OA & $\cdot, \pi$ & $\cdot, 07$ & $\cdot, 07$ & أسلوب المعاملة المتساهل لللأم & الرهاب الاجتاعي \\
\hline$* \mid r 7, \varepsilon q$ & سז, & $\cdot, \mathrm{OV}$ & $\cdot, 10$ & أسلوب المعاملة المتسلط للأب & \\
\hline
\end{tabular}


يظهر جدول ^ أن أساليب المعاملة الوالدية؛ المتساهل لصورة

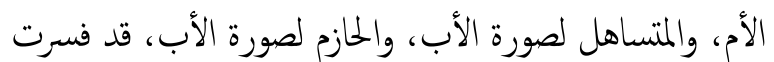

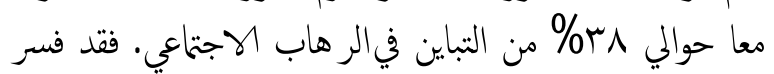

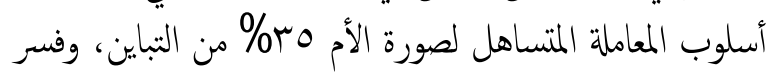

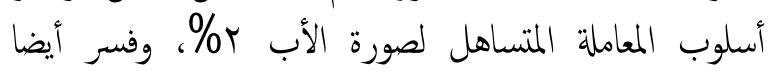

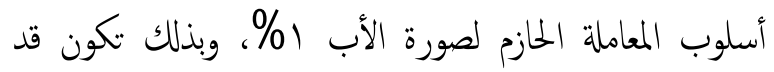

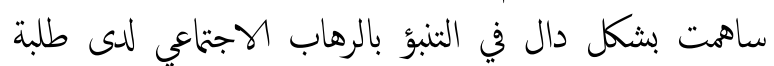

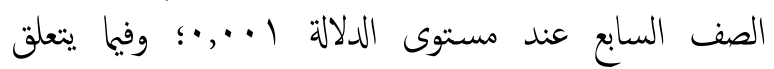

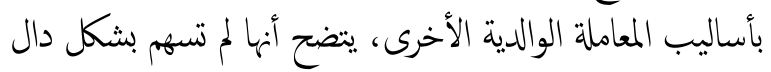

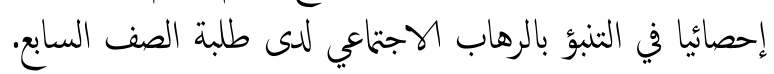

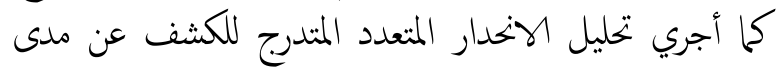
مساهمة كل أسلوب من أساليب المعاملة الوالدية في التنبؤ الماتئ بالرهاب الاجتماعي لدى طلبة الصف الثامن، ويين جدول الثبل نتاجُج هذا التحليل. يظهر جدول 9 أن أساليب المعاملة المتساهل لصورة الأب،

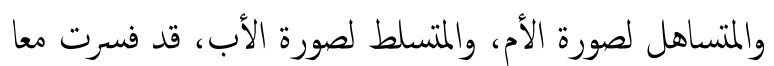

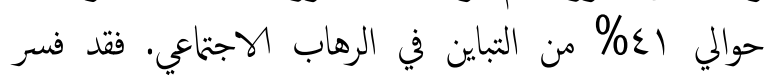

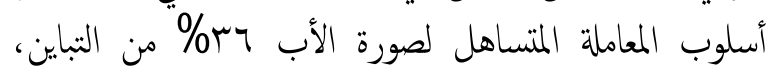

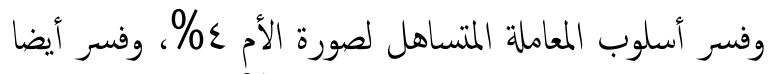

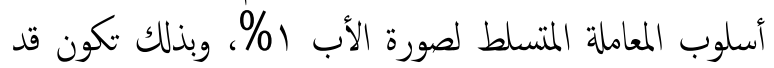

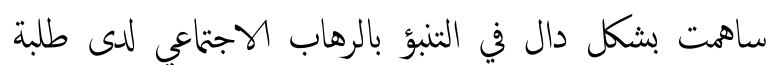

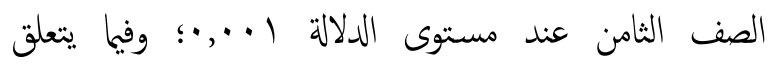

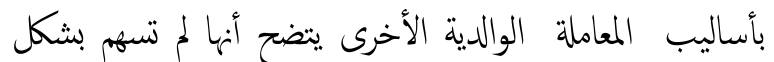

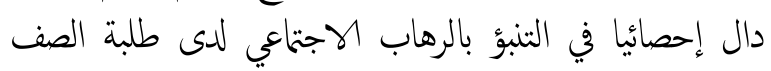

لصورة الأم ابr\% من التباين، وفسر أسلوب المعاملة المتسلط

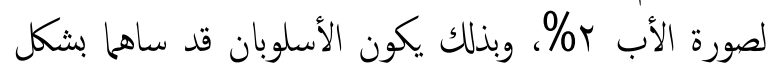

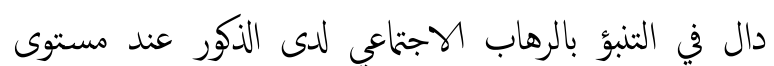

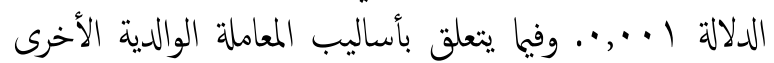

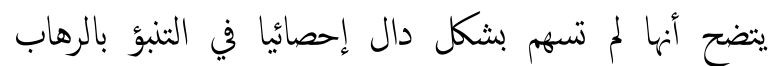

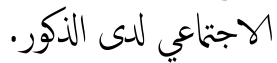

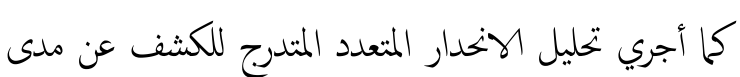

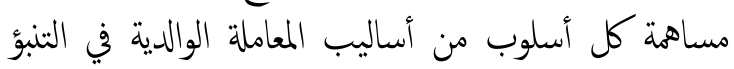

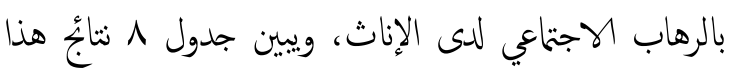
التحليل.

يظهر جدول 1 أن أسلوبي المعاملة الوالدية؛ المتساهل لصورة

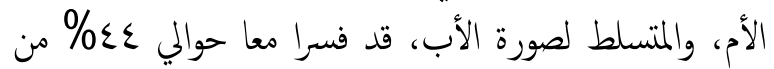

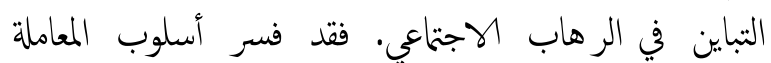

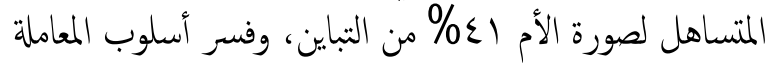

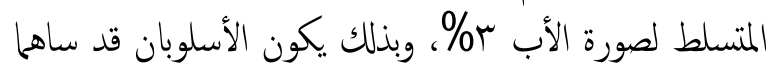

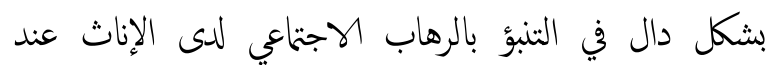

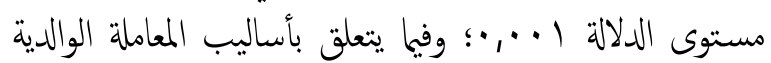

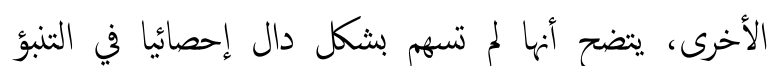

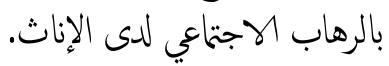

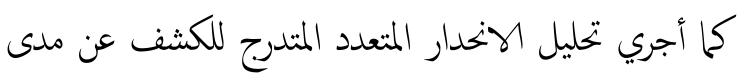

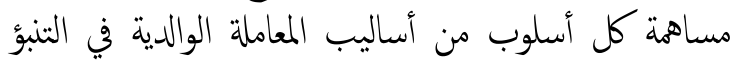

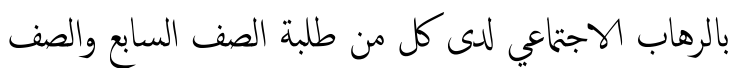

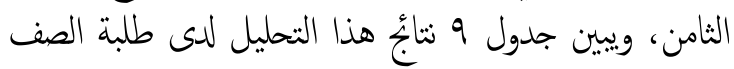

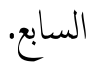

\section{جدول 1}

تابُّ تحليل الانحدار المتعدد المتدرج لكل أسلوب من أساليب المعاملة الوالدية في التنبؤ بالرهاب الاجتماعي لدى الإناث

\begin{tabular}{|c|c|c|c|c|c|}
\hline قيمة ف & التباين المفسر & الارتباط المتعدد & معامل الانحدار المعياري & المتنبئات & المتغير التابع \\
\hline 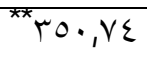 & $\cdot, \Sigma 1$ & $\cdot, 7 \varepsilon$ & $\cdot, 7 \varepsilon$ & أسلوب المعاملة المتساهل للام & الرهاب الاجتماعي \\
\hline **ar, & $\cdot, \varepsilon \varepsilon$ & $\cdot, 77$ & $\cdot, r_{1}$ & أسلوب المعاملة المتسلط للأب & \\
\hline
\end{tabular}

9

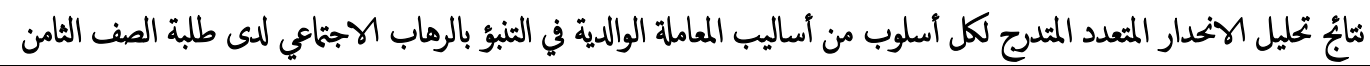

\begin{tabular}{|c|c|c|c|c|c|}
\hline قيمة ف & المفر & المارتباط & معامل الانحدار المعياري & المتنبئات & المتغير التابع \\
\hline *tr. 9,190 & $\cdot, \pi 4$ & $\cdot, 7$. & $\cdot, 7$ & أسلوب المعاملة المتساهل للأب & الرهاب الاجتّاعي \\
\hline$* * \mid \vee \wedge, \varepsilon \backslash \wedge$ & • & זד, & $\cdot, r q$ & أسلوب المعاملة المتساهل للأم & \\
\hline$* *, r \varepsilon, r \vee q$ & $\cdot, \leqslant 1$ & $\cdot, T \varepsilon$ & 0 & أسلوب المعاملة المتسلط للأب & \\
\hline
\end{tabular}


المسترشدين، وفي مثل هذه الحالات، مـن الأفضل أن يلتقي

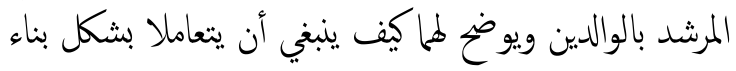

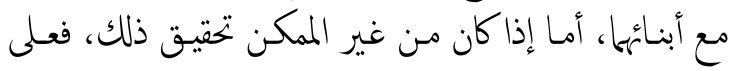

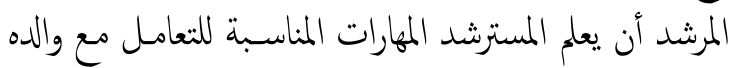

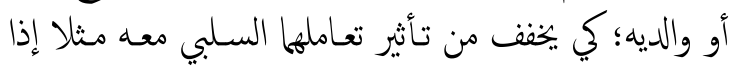

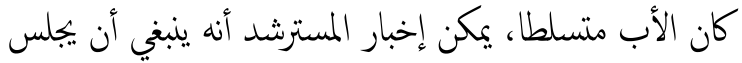

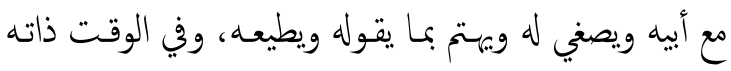

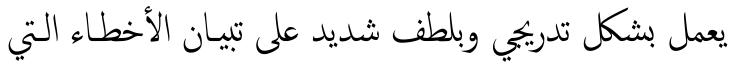

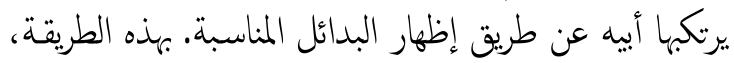

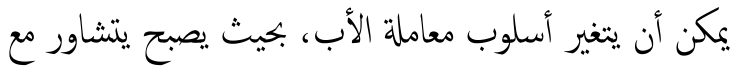

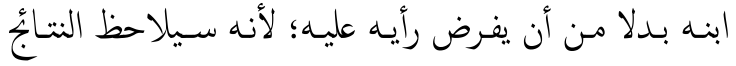
الإيجابية التي أدى إليها الحوار مع ابنه. وأشارت النتائُ أن من الأسباب الرئسة لظهور الرهاب

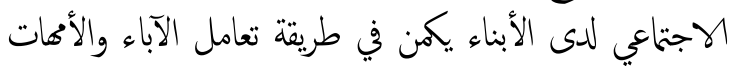

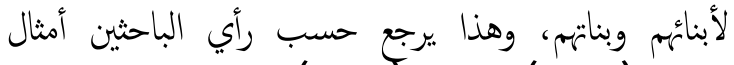

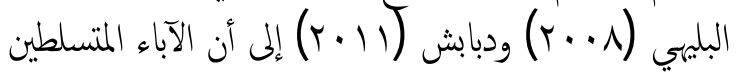

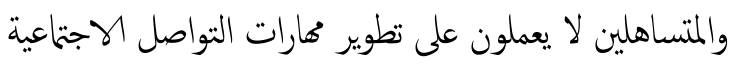

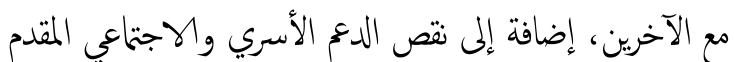

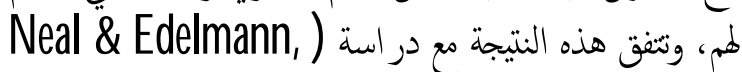

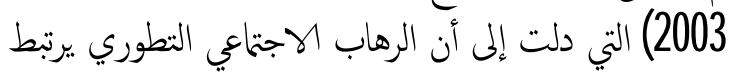

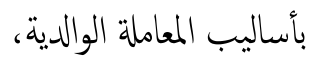

كما أظهرت النتائُ أن أسلوبي المعاملة المتسلط والمتساهل

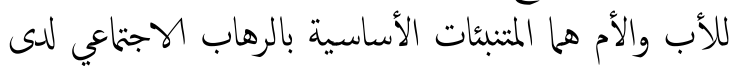

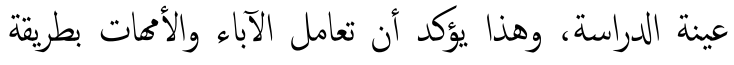
غير سليمة، وغير صحيحة وعدم توفر جو ملائم في البيئة

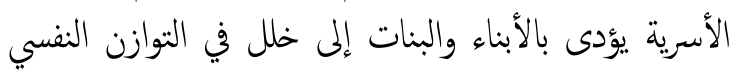

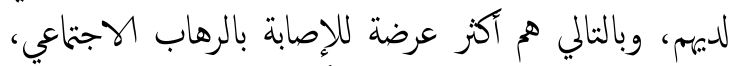

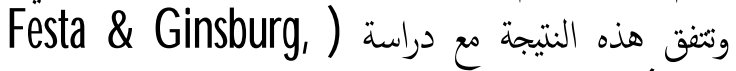

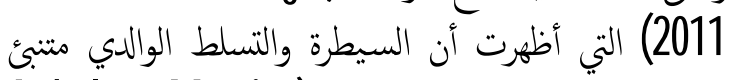

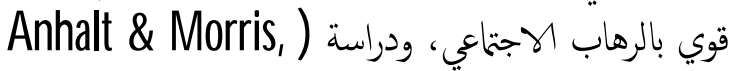

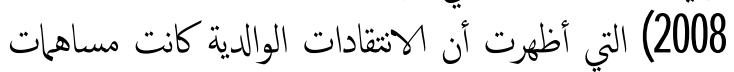
قوية في التنبؤ بالرهاب الهرت آنتاعي. التوصيات' في ضوء نتاجُ الدراسة الحالية، فإنه يمكن الوصول

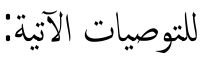

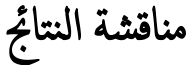

تنير نتائُ الدراسة إلى أن الآباء والأحمات يميزون في أساليب

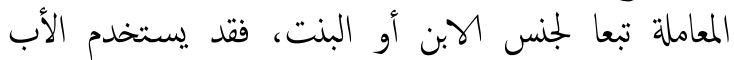

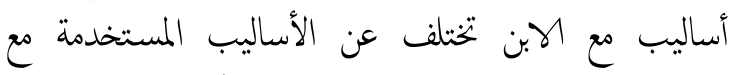

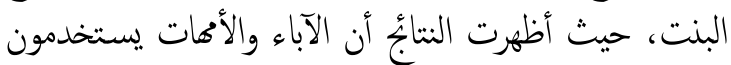

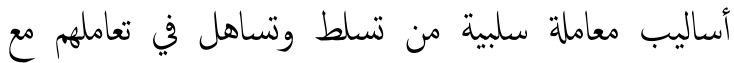

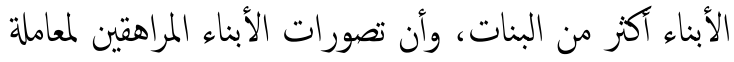

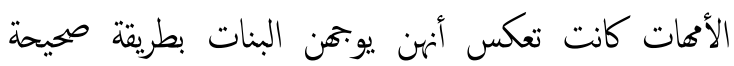

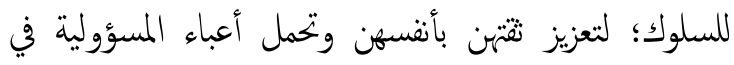
الأعمال المختلفة وهذه هي النظرة السائدة لكثير من الآباء

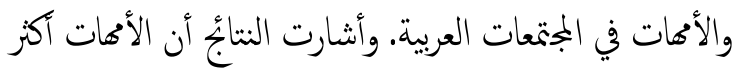

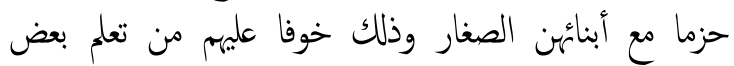

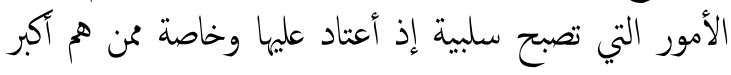

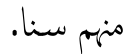

وقد تبين أن الوالدان الحازمان يحققان لأبنائهم وبناتهم مستوى

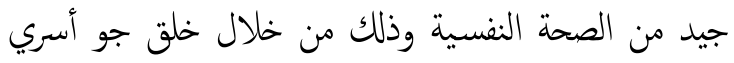

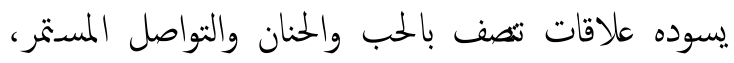

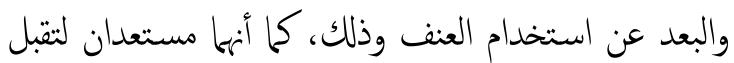
وبجات نظرهم ومناقشتها للوصول إلى تعزيز تقة الأبناء بأنفسهم، وجعلهم يشعرون بالرضا والسعادة الذي بدوره يعمل على تخفيف الاضطرابات النفسية والانفعالية، وتختلف هذه ولنه النتيجة مع دراسة (Yeganeh al et., 2006) أنه لا يوجد اختلاف بين أساليب المعاملة الوالدية بين الآباءو والأهمات. يرى الباحثان أن الإناث ينشأن في بيئة أو بيت يدع السلوك

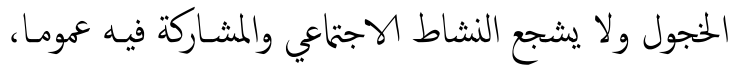

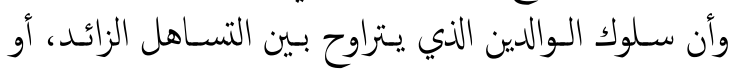

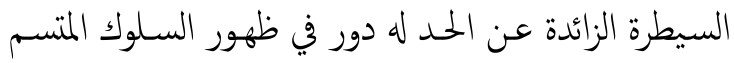

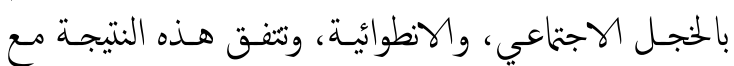
دراسة (Walters \& Inderbitzen, 1998) التي أشارت إلى أن أصابة الطالبات بالرهاب أكثر من الطلاب.

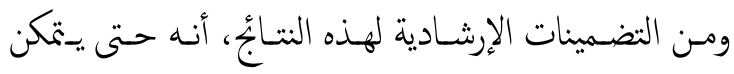

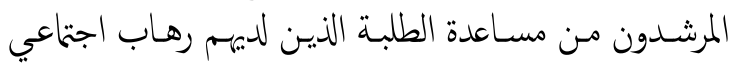

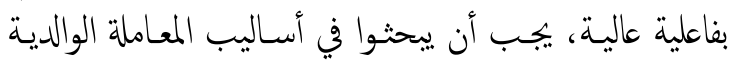

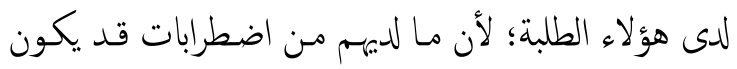

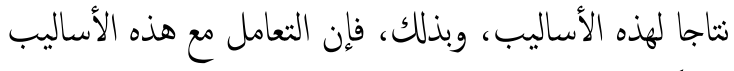

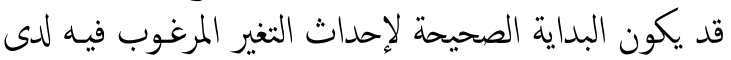


مجلة اتحاد الجامعات العربية للترية وعلم النفس، جامعة دمشق ، سوريا.

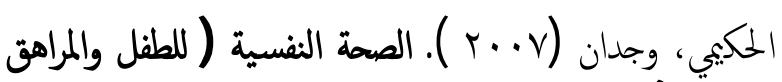

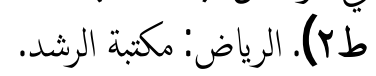

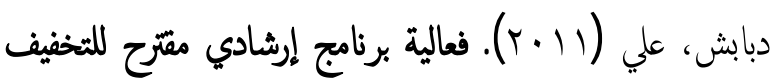

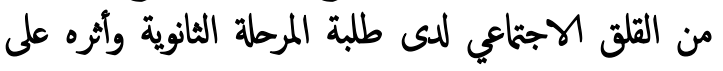
ثقدير الذات. رسالة ماجستير غير منشورة، جامعة الأزهر،

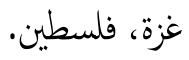

شاهين، فرنسيس وجرادات، عبدالكريم (2012)، مقارنة العلاج

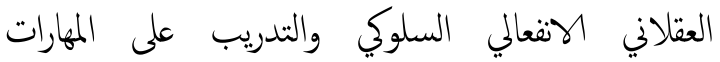

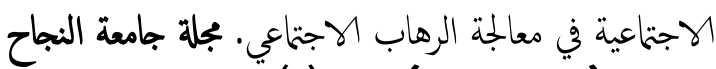

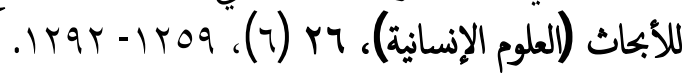

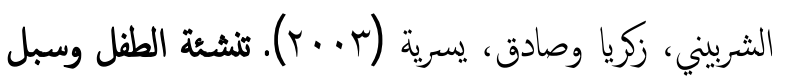

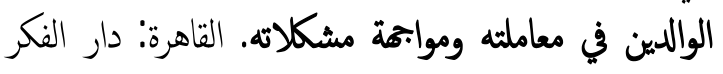
العربي.

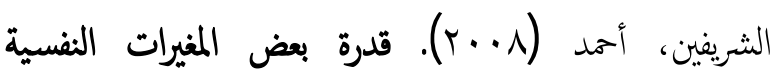

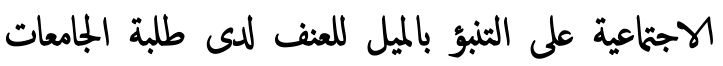

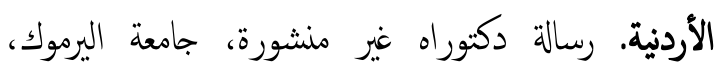
المماكة الأردنية الهاثنمية.

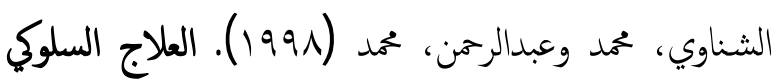

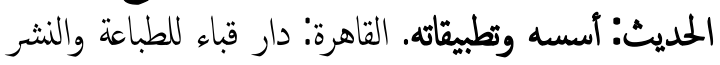
والتوزيع.

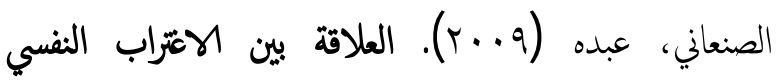

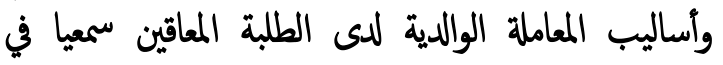

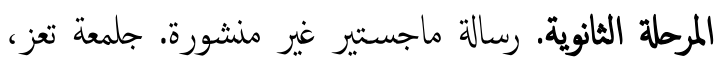

$$
\text { الجمهورية اليمنية. }
$$

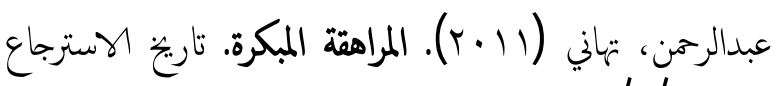

http://www.al•

islam.com/Content.aspx?pageid=1131\& ContentID $=2345$

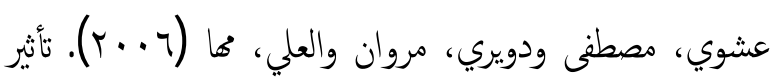

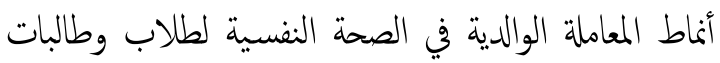

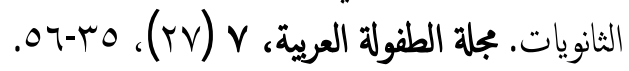

1. إجراء المزيد من الدراسات التي تبحث علاقة أساليب المعاملة الوالدية مع اضطرابات المرات الفعالية تبحث عاتية

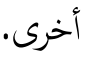
r. إجراء بحوث أوسع في تشخيص اضطراب الرهاب

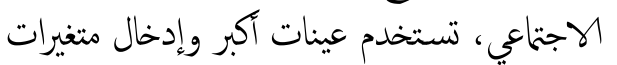

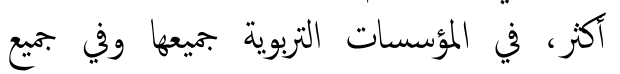
المراحل التعليمية. r. حث أولياء الأمور على توفير فرص لأبنائهم ليتعلموا

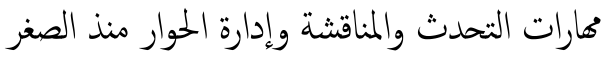
لأن ذلك يمنع ظهور الرهاب الاجتماعي لديهمי ع. إجراء دراسات تتناول علاقة متغيرات أسرية أخرى بالرهاب الاجتماعي؛ ليتضح دور الأسرة في ظهور الرهاب الاجتماعي لدى الأبناء.

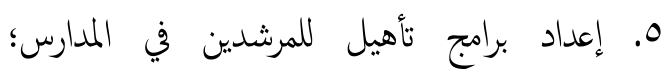

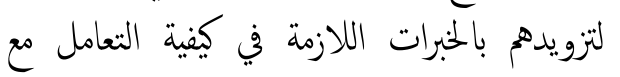
الطلبة المرهوبين اجتاعيا.

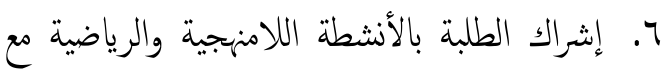

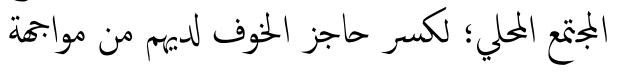
الآخرين. V. زيادة وعي الآباء بأساليب المعاملة الوالدية، وعلاقها بالصحة النفسية لدى الأبناء. A. تصميم برامج وقائية للتعليم النفسي، والتدريب على الني

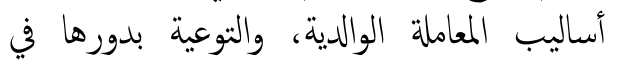
تطوير الاضطرابات النفسية.

$$
\text { المراجـ }
$$

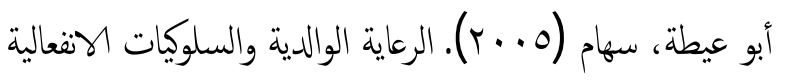

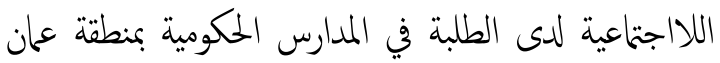

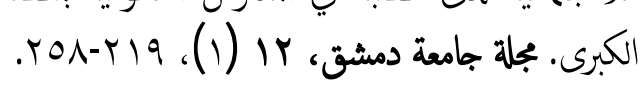

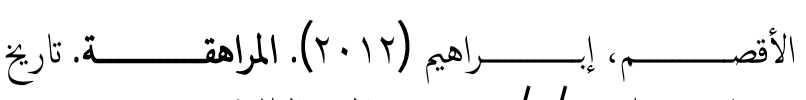

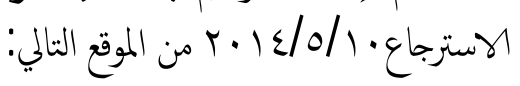
http://www.iu.edu.sa/administrations/Educational/Teacher/P ages/Adolescence.aspx

جرادات، عبدالكريم والجوارنة، أحمد (مقبول للنشر).علاقة أساليب المعاملة الوالدية بالأعراض الاكتئابية وسمة القلقد 
American Psychiatric Association. (1994). Diagnosis and statistical manual of mental disorder (4th Ed.). Washington, D.C.: American Psychiatric Association.

Anhalt, K., \& Morris, T.(2008). Parenting characteristics associated with anxiety and depression: A multivariate approach. Journal of Early and Intensive Behavior Intervention, 5 (3), 122-137.

Baumrind, D. (1989). Rearing competent children. In W. Damon (Ed.), Child development today and tomorrow (pp. 349378). San Francisco: Jossey-Bass.

Baumrind, D. (1991). The influence of parenting style on adolescent competence and substance use. Journal of Early A dolescence, 11 (1), 56-95.

Bobes, J. (1999). Social anxiety, social phobia: The course of illness prior to treatment. International Journal of Psychiatry in Clinical Practice, 3 (suppl 3), 21-23.

Bruch, M. (1989). Familial and developmental antecedents of social phobia: Issues and findings. Clinical Psychology Review, 9, 3747.

Cenkseven-Onder, F., Kirdok, O.,\& Isik, E. (2010). High school students' career decision-making pattern across parenting styles and parental attachment levels. Electronic Journal of Research in Educational Psychology, 8 (1), 263-280.

Chaleby, K., \& Raslan, A. (1990). Delineation of social phobia in Saudia Arabians. Social Psychiatry \& Psychiatric Epidemiology, 25 (6), 324-327.

Dwairy, M. (2004). Parenting styles and psychological adjustment of Arab adolescents. Transcultural Psychiatry, 41(2), 233-252.

Festa, C., \& Ginsburg, G. (2011). Parental and peer predictors of social anxiety in youth.Child Psychiatry \& Human D evel opment, 42 (3), 291-306.

First, M., Frances, A., \& Princus, H.(1999). Diagnosis and statistical manual of mental disorder (4th Ed.). diagnostics differentials. Masson, Paris.

Leary, M., \& Meadows, S. (1991). Predictors, elicitors, and concomitants of social bluching. Journal of Personality and Social Psychology, 60, 245-262.

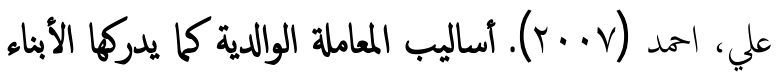

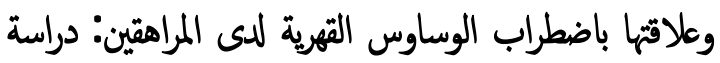

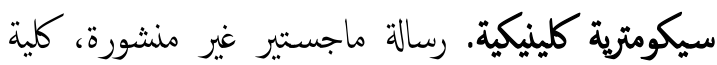

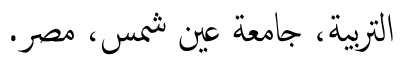

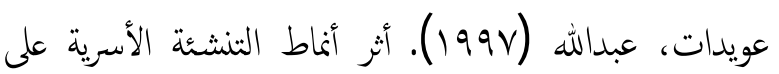

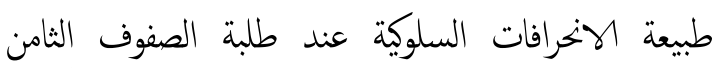

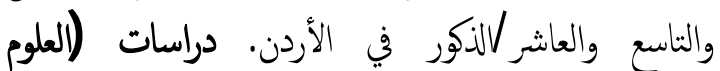

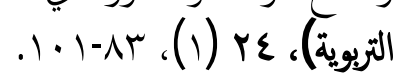

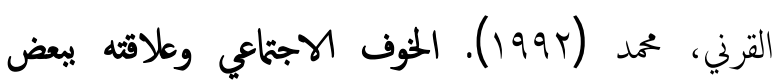

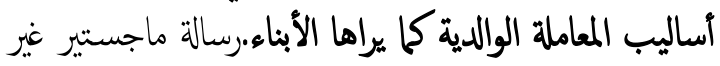
منشورة، جامعة الملك سعود، الرياض - المملكة العربية السعودية. - ملنووة

كوري، جيرالد (1990). الإرشاد والعلاج النفسي بين النظرية

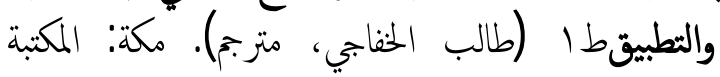
الفيصلية.

المالح، حسان (1990)، دراسة علمية للاضطراب النفي الني

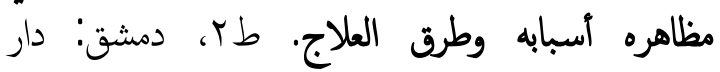

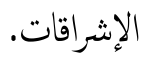

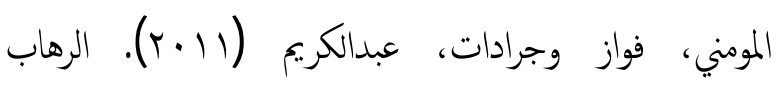

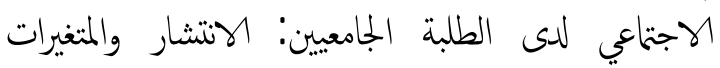

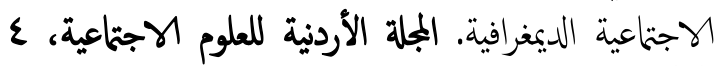

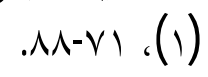

نادر، نجوى (1991) ). معاملة الوالدين للطفل وعلاقتها بالتحصيل الدراسي في مرحلة التعليم الإيتدائي - دراسة ميدانية في محافظة دمشق وريف دمشق رسالة ماجستير غير الإني منشورة، دمشق - سوريا.

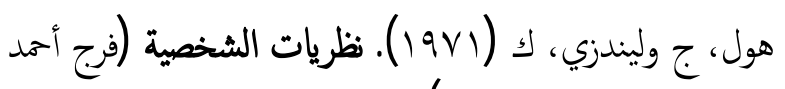

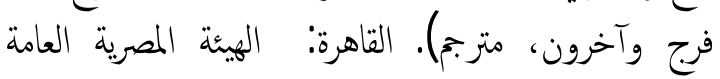
للتأليف والنشر واخرو، متر 
Loukas, A. (2009). Examining temporal associations between perceived maternal psychological control and early adolescent internalizing problems. Journal of A bnormal Child Psychology, 37 (8), 1113-1122.

Mattick, P., \& Clarke, C. (1998). Development and validation of measures of social phobia scrutiny fear and social interaction anxiety. Behaviour Research \& Therapy, 36, 455-470.

Neal, J., \&Edelmann, R. (2003). The etiology of social phobia: Toward a developmental profile. Clinical Psychology Review, 23 (6), 761-786.

Rachman, S. (1998). Anxiety psychology. Press LTD, London.

Rork, K., \& Morris, T. (2009). Influence of parenting factors on childhood social anxiety: Direct observation of parental warmth and control. Child ad Family Behavior Therapy, 31 (3), 220-235.

Sheehan, D. (1987). Simple and effective treatment of agoraphobia. New York: Hawthorn Book.

Van Oort, F., Greaves-Lord, K., Ormel, J., Verhulst, F., \& Huizink, A. (2011). Risk indicators of anxiety throughout adolescence: The TRAILS study. D epression \& A nxiety, 28 (6), 485-494.

Veale, D. (2003). Treatment of social phobia. Advances in Psychiatric Treatment, 9, 258264.

Walters, K., \& Inderbitzen, H. (1998). Social anxiety and peer relations among adolescents: Testing a psychobiological model. Journal of A nxiety Disorders, 12 (3), 98-183.

Yeganeh, R., Beidel, D., \& Turner, S. (2006). Selective mutism: More than social anxiety? D epression \& Anxiety, 23 (3), 117123.

Zubeidat, I., Parra, A., Sierra, J., \& Salinas, J. (2008). Assessment of factors associated to social anxiety and other psychopathologies in adolescents. Salud M ental, 31 (3), 189-196. 


\section{ملحت}

مقياس أساليب المعاملة الوالدية

\begin{tabular}{|c|c|c|c|c|c|}
\hline 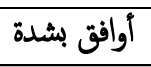 & 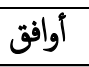 & 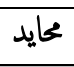 & لا لا أوافق & لا أوافق بشدة & 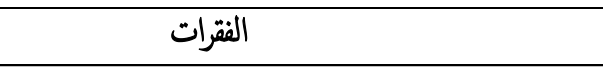 \\
\hline \multicolumn{6}{|c|}{ صورة الأب } \\
\hline 0 & $\varepsilon$ & $r$ & r & 1 & I ا يفرض رأيه بشدة أثثاء المناقشات (ط) \\
\hline 0 & $\varepsilon$ & $r$ & r & 1 & r. يوجه سلوكي بمنطق ونظام اح) \\
\hline 0 & $\varepsilon$ & $r$ & r & 1 & rا. يغضب مني عندما أحاول مخالفته في الرأي. (ط) \\
\hline 0 & $\varepsilon$ & $r$ & r & 1 & ع. ، يهمل مشكلات الأبناء داخل الأسرة. (هـ) \\
\hline 0 & $\varepsilon$ & $r$ & r & 1 & 0. يعمل على تعزيز الثقة المتبادلة بينه وبيني احج) \\
\hline 0 & $\varepsilon$ & $r$ & r & 1 & 1. يتصيد أخطائي ويستغلها لمصلحته الخاصة. (ط) \\
\hline 0 & $\varepsilon$ & $r$ & r & 1 & V. يعزز لدي الشعور بالمسؤولية، (ح) \\
\hline 0 & $\varepsilon$ & $r$ & r & 1 & م، لا يتدخل بما أفعله ولا يوجه سلوكي. (هـ) \\
\hline 0 & $\varepsilon$ & $r$ & r & 1 & 9 9. يعاقبني عندما لا أحقق طموحاته (ط) \\
\hline 0 & $\varepsilon$ & $r$ & $r$ & 1 & • ا ب يراعي حاجات أفراد الأسرة، اح)| \\
\hline 0 & $\varepsilon$ & $r$ & r & 1 & 11 11 يتصف بضعف القدرة على تنظيم أمور الأسرة. (هـ) \\
\hline 0 & $\varepsilon$ & $r$ & $r$ & 1 & r ا ا يجبرني على تنفيذ ما يريد مني. (ط) \\
\hline 0 & $\varepsilon$ & $r$ & $r$ & 1 & rا ا. تتسم قراراته بعدم المسؤولية واللامبالاة. (هـ) \\
\hline 0 & $\varepsilon$ & $r$ & r & 1 & ع ا يعمل على تحقيق التآلف داخل الأسرة. احح] \\
\hline 0 & $\varepsilon$ & $r$ & r & 1 & 10 ب يحاول التنصل من المسؤولية. (هـ) \\
\hline \multicolumn{6}{|c|}{ صورة الأم } \\
\hline 0 & $\varepsilon$ & $r$ & r & 1 & ) ا تقرض رأها بشدة أثناء المناقشات (ط) \\
\hline 0 & $\varepsilon$ & $r$ & $r$ & 1 & r. r. توجه سلوكي بمنطق ونظام، اح) \\
\hline 0 & $\varepsilon$ & $r$ & $r$ & 1 & rا. تضضب مني عندما أحاول مخالفها في الرأي. (ط) \\
\hline 0 & $\varepsilon$ & $r$ & r & 1 & ع. تهمل مشكلات الأبناء داخل الأسرة. (هـ) \\
\hline 0 & $\varepsilon$ & $r$ & r & 1 & 0. تعمل على تعزيز الثقة المتبادلة بينها وبيني، احح) \\
\hline 0 & $\varepsilon$ & $r$ & r & 1 & 7. تتصيد أخطائي وتستغلها لمصلحتها الخاصة. (ط) \\
\hline 0 & $\varepsilon$ & $r$ & r & 1 & VI. تعزز لدي الشعور بالمسؤولية، اح]) \\
\hline 0 & $\varepsilon$ & $r$ & r & 1 & م، لا تدخل بما أفعله ولا توجه سلوكي. (هـ) \\
\hline 0 & $\varepsilon$ & $r$ & r & 1 & 9. تعاقبني عندما لا أحقق طموحلها. (ط) \\
\hline 0 & $\varepsilon$ & $r$ & r & 1 & • ا ـ تراعي حاجات أفراد الأسرة. اح) \\
\hline 0 & $\varepsilon$ & $r$ & r & 1 & 11 1 ـ تصف بضعف القدرة على تنظيم أمور الأسرة. (هـ) \\
\hline 0 & $\varepsilon$ & $r$ & r & 1 & r) I ا تجبرني على تنفيذ ما تريد مني (b) \\
\hline 0 & $\varepsilon$ & r & r & 1 & با I ا تتسم قراراتها بعدم المسؤولية واللامبالاة. (هـ) \\
\hline 0 & $\varepsilon$ & $r$ & r & 1 & ع (ا تعمل على تحقيق التآلف داخل الأسرة، اح) \\
\hline 0 & $\varepsilon$ & $r$ & r & 1 & 10 ـ تحاول التنصل من المسؤولية. (هـ) \\
\hline
\end{tabular}

